ORNL/M-1262

\title{
MODIFIED SEASONAL FACTORS IN EXPONENTIAL SMOOTHING
}

\author{
J. Scott Armstrong* \\ Ho-Ling Hwang \\ Jeff Bandyt \\ *The Wharton School, University of Pennsylvania \\ †The University of Tennessee
}

September 1990

\begin{abstract}
Prepared for the
NAVY PERSONNEL RESEARCH AND DEVELOPMENT CENTER

San Diego, California

under Interagency Agreement DOE 1730-1730-A1
\end{abstract}

Prepared for the

OAK RIDGE NATIONAL LABORATORY

Oak Ridge, Tennessee 37831

operated by

MARTIN MARIETTA ENERGY SYSTEMS, INC.

for the

U.S. DEPARTMENT OF ENERGY

under Contract No. DE-AC05-84OR21400 


\section{CONTENTS}

LIST OF TABLES $\ldots \ldots \ldots \ldots \ldots \ldots \ldots \ldots \ldots \ldots \ldots \ldots \ldots \ldots, v$

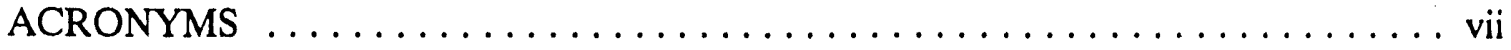

ABSTRACT $\ldots \ldots \ldots \ldots \ldots \ldots \ldots \ldots \ldots \ldots \ldots \ldots \ldots \ldots \ldots \ldots \ldots \ldots \ldots \ldots$, ix

1. INTRODUCTION $\ldots \ldots \ldots \ldots \ldots \ldots \ldots \ldots \ldots \ldots \ldots \ldots \ldots \ldots \ldots \ldots \ldots \ldots$

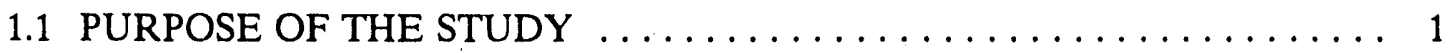

1.2 RATIONALE FOR USE OF MODIFIED SEASONAL FACTORS IN

FORECASTING $\ldots \ldots \ldots \ldots \ldots \ldots \ldots \ldots \ldots \ldots \ldots \ldots \ldots \ldots \ldots, 2$

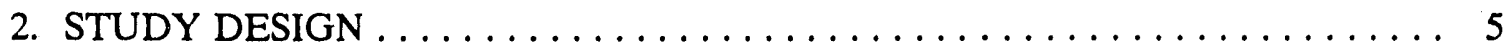

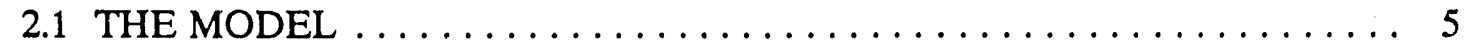

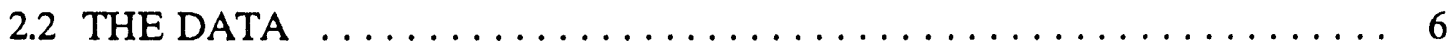

2.3 THE MODIFIER $\ldots \ldots \ldots \ldots \ldots \ldots \ldots \ldots \ldots \ldots \ldots \ldots, 8$

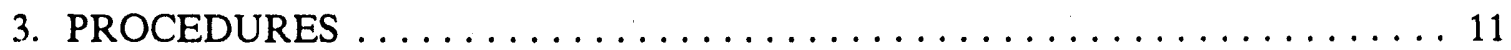

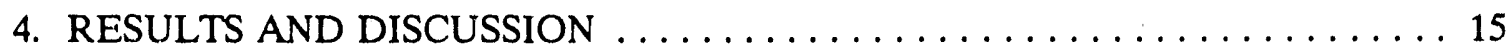

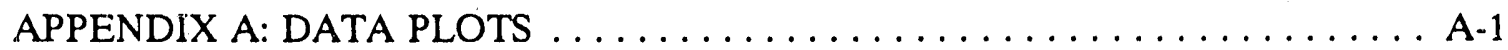

APPENDIX B: USE OF SUBJECTIVE INFORMATION $\ldots \ldots \ldots \ldots \ldots \ldots$ B-1 


\section{LIST OF TABLES}

Table

Page

1. Example data from a typical NPRDC dataset (fourth quarter of 1975) . . . . . 6

2. A comparison of the Gardner and Holt-Winters methods in five test series; ten-year forecasting . . . . . . . . . . . . . . . . . . . 12

3. A summary of MAPE comparisons for $\gamma=0.2 \ldots \ldots \ldots \ldots \ldots \ldots \ldots$

4. A summary of MAPE comparisons for $\gamma=0.5 \ldots \ldots \ldots \ldots \ldots \ldots \ldots$

5. A summary of MAPE comparisons for $\gamma=0.7 \ldots \ldots \ldots \ldots \ldots \ldots \ldots \ldots$

6. A comparison of the proposed modified seasonal factor, Gardner's, and the Naive- 3 models on series LOS $=1-31$ for $\gamma=0.2 \ldots \ldots \ldots \ldots$ 


\section{ACRONYMS}

LOS Length of Service

MAE Mean Absolute Error

MAPE Mean Absolute Percent Error

ME Mean Error

NPRDC Navy Personnel Research and Development Center

RMSE Root Mean Square Error

USN U.S. Navy

USNR U.S. Navy Reserve 


\begin{abstract}
Current practice uses statistical tests to determine whether seasonal factors should be applied in a given forecasting situation. Research suggests that an optimal policy might lie somewhere between using full seasonal factors and using no seasonal factors on series. This research proposes and tests use of a modified seasonality factor. Modified seasonal factors reduce the emphasis on the seasonal adjustments when forecasts are made. The adjustments account for errors in the estimation of the factors and for possible changes in the factors over the forecast horizon. An analysis of data from U.S. Navy personnel inventories was conducted to test the use of a modified seasonality factor.

Modified seasonal factors led to improved accuracy for predictions of inventories by paygrade using quarterly data from the Navy Personnel Research and Development Center (NPRDC). Under certain selections of factors, the mean absolute percent error (MAPE) was reduced by $4.4 \%$. No gain was obtained, however, for the inventories by length of service. It is expected, but not shown here, that the modified seasonal factors will only be of value for series where the estimated seasonal factors show a substantial variation across the year.
\end{abstract}




\section{INTRODUCTION}

Statistical and econometric forecasting methods are critical components of the Navy's personnel force management system. A wide variety of forecasting models is currently in use in the Navy's officer and enlisted force management systems. Because the Navy is continually changing and because policy planning demands accurate forecasts, there is a constant need to improve existing methods or develop new forecasting techniques. This research investigated a new approach to use of seasonality factors. The validation of this method used Navy enlisted personnel data.

\subsection{PURPOSE OF THE STUDY}

Current practice uses statistical tests to determine whether seasonal factors should be applied in a given forecasting situation. These tests lead to a decision either to employ a seasonal adjustment or not. Prior research has shown that this strategy for using seasonal factors improves the accuracy of extrapolation forecasts in most cases. However, there have been studies where accuracy was poorer (Groff 1973; Nelson 1972). These results suggest that the optimal policy might lie somewhere between using full seasonal factors and using no seasonal factors on series.

Use of a modified seasonal factor could help with two aspects of the forecasting model. The first relates to problems with the estimation of seasonal factors. This calls for an "estimation modifier." The second relates to the deterioration of the seasonal factors over the forecast horizon. This calls for a "horizon modifier." 
The purpose of this study, then, is to determine whether use of modified seasonal factors leads to improved forecasting accuracy. The rationale for the use of modified seasonal factors is given below. Section 2 is a description of the study design, and Section 3 discusses the procedures used. Finally, results from an analysis of U.S. Navy personnel inventory data are presented in Section 4.

\subsection{RATIONALE FOR USE OF MODIFIED SEASONAL FACTORS IN FORECASTING}

Statistical tests for seasonality prove useful in many cases. But they lead to an all or nothing strategy for the use of seasonal factors. Some situations may benefit from an intermediate strategy. For example, there may be cases for which the statistical tests recommend no seasonal adjustment even though modest adjustments would be useful.

Seasonal factors are often difficult to estimate. This occurs because the observed variations include the true factors plus errors. To the extent that the estimates of the seasonal factors contain errors, their use will add errors to the forecasts. This problem is of particular importance when data are limited or where they contain extreme values.

Furthermore, statistical estimates do not take advantage of the forecaster's subjective information. In particular, the forecaster may have information about the causal factors that contribute to the seasonality. This information should influence the estimation of seasonal factors. ${ }^{1}$ When good knowledge of the reasons leading to seasonal variation exist, the forecaster should be willing to put more emphasis on seasonal factors.

\footnotetext{
${ }^{1}$ For example, a forecaster, knowing that people drink more beverages in the warmer months, may decide that seasonal factors should be used in forecasting monthly sales for a given brand of beer. Another example is that the firms in a particular industry may typically have marketing promotions during certain holidays, such as at Easter.
} 


\section{$3 / 4$}

Because the factors that affect seasonality may change as the forecast horizon is increased, we propose that the seasonal factors be modified as the horizon increases. That is, it makes sense to use the horizon modifier to reduce the impact of the seasonal adjustments in the face of increasing uncertainty. 


\section{STUDY DESIGN}

This section describes the model to ve tested, the data, and the modifier.

\subsection{THE MODEL}

The study was carried out using well-accepted extrapolation methods, the Holt-Wint :rs model and the Damped Trend Model by Gardner and McKenzie. Multiplicative seasonal factors were used in this study because of their importance in many situations. Although additive factors are likely to be relevant for some situations, such as for bounded data, these types of data were not examined.

The procedures in this study pertain only to how seasonal factors should be used in the forecasting model. The calculation of seasonal factors from the historical data is assumed to be done in the traditional manner. Our concern here is with how to modify these factors to prepare the forecasts.

The modified seasonal factor, $\mathrm{S}^{\prime}$, is defined as follows for the multiplicative case:

$$
S_{j}^{\prime}=M_{h}+\left(1-M_{h}\right) S_{j}
$$

where $\mathrm{j}$ represents the time period (e.g., month), and $\mathrm{M}_{\mathrm{h}}$ is the modifier for year $\mathrm{h}$ in the forecast horizon (the same modifier applying to all periods in the year). $\mathrm{M}_{\mathrm{b}}$ is bounded between 0 and 1 . When it is 0 , no modifying occurs; that is, the full seasonal factors are used. When it is 1 , no seasonal factors are used.

The subscript " $h$ " allows for the modifier to be changed over the years of the forecast horizon. The modifier would typically increase over the forecast horizon. In other words, less attention should be paid to the historically estimated seasonal factors as the forecast horizon increases. 
The following model is suggested, then, for the selection of a modifier, $M_{h}$, which must be less than or equal to 1.0 :

$$
M_{b}=d^{-\gamma *} h^{\lambda}, \quad \text { for } d \geq 1 \text { and } 0 \leq \gamma, \lambda \leq 1 \text {, }
$$

where $d$ represents the number of cycles (years) of data in the calibration sample, $\gamma$ is the parameter to adjust for errors in the historical estimation, $h$ is the number of periods ahead in the forecast horizon, and $\lambda$ is a parameter to adjust for the deterioration of the factors over the forecast horizon. If the calculated modifier, $\mathrm{M}_{\mathrm{b}}$, exceeds 1.0 , then the value 1.0 should be used.

Search routines would be used in an effort to obtain good estimates for the parameters $\gamma$ and $\lambda$. Subjective estimates may also help in determining the best value for $\gamma$. A higher $\gamma$ should be used if the experts in that situation expect substantial changes in the seasonal pattern over the forecast horizon. These changes may be due to increasing uncertainty or to planned changes that affect the seasonal pattern.

\subsection{THE DATA}

Three sets of quarterly data on Navy enlisted personnel were made available by the Navy Personnel Research and Development Center (NPRDC) for this research. These datasets differ by the branch of the Navy that they represent: regular active duty Navy (USN), reservists on active duty (USiJR), and all Navy (USN + USNR). The datasets contain quarterly enlisted personnel inventories broken down by paygrade (E1-E9) and length of service (LOS) in years from March 1957 to June 1988. Table 1 shows an example of the data structure for a typical quarter in the dataset. There are 32 records per quarter, representing LOS 1-31 and the LOS total (coded as 32). Each record contains information on the quarter and year of the record, number of enlisted personnel for each 
Table 1. Example data from a typical NPRDC dataset (fourth quarter of 1975)

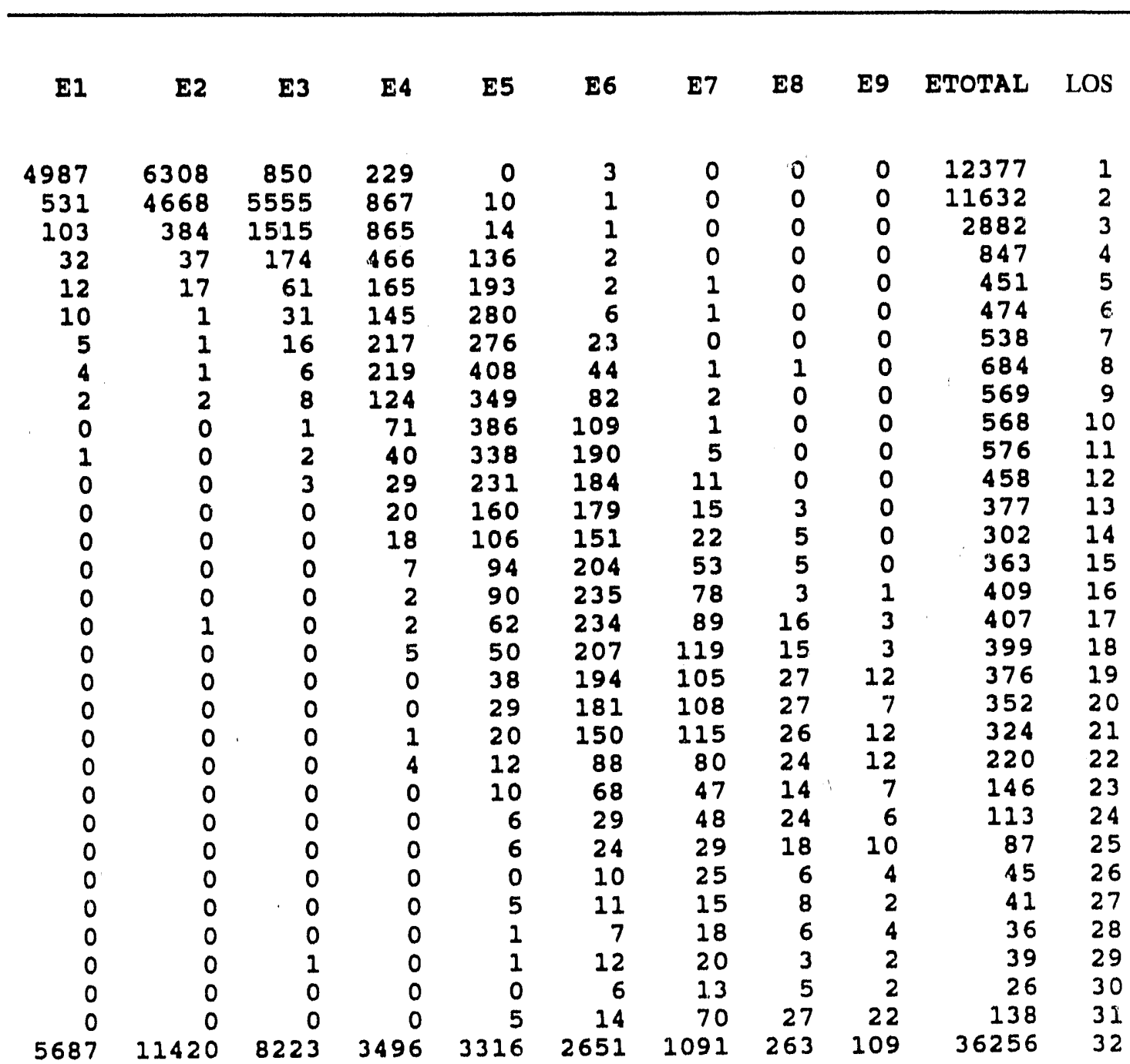


paygrade (E1-E9), total (sum over all paygrades in that record), and the LOS cell value (1-32). For example, there are 384 people in paygrade E2 with three years of service.

Summary data were extracted and used in evaluating the proposed method on modified seasonal factors. The primary emphasis of the study presented in this report was placed on the 18 series that consisted of quarterly population totals on each paygrade (E1-E9) for the USN and for the USNR. Data from the first quarter of 1957 to the second quarter of 1978 in each series were used in the forecasting while the remaining data, 1979-1988, were used to test the model accuracy. For each series, except paygrades E8 and E9, data for 86 quarters were used to forecast the ten following quarters, and the results were compared to their corresponding actual populations to obtain estimates of errors. In order to reduce possible difficulties that might arise during the testing of seasonality, the zero populations that appeared at the beginning of series E8 and E9 were eliminated from the analysis, which resulted in slightly shorter series. Graphical representation of some of these time series are displayed in Appendix A, Figures A.1-A.4. A smaller scale investigation was later carried out with 31 series broken down by LOS instead of paygrade. These time series consist of quarterly totals on each LOS (1-31) for the dataset USN. Examples of these series are presented in Figures A.5-A.8.

\subsection{THE MODIFIER}

The rationale behind this study was to modify the ordinary seasonal index so that a more accurate forecast can be made in extrapolation procedures. Therefore, the important task in this research is to search for a proper modifier for these time series. The suggested modifier, as stated in an earlier section, was defined as a function of the number of available cycles of data (d) and the number of cycles in the forecast horizon (h) with values bounded at 1 . That is, 
$M_{v}=\operatorname{Min}\left\{1, d^{*} * h^{2}\right\}$, for $d \geq 1$ and $0 \leq \gamma, \lambda \leq 1$,

where $\operatorname{Min}\{a, b\}$ represents the value of $a$ or $b$, whichever is smaller. The concept of using subjective information about causality was also examined and is described in Appendix B. 


\section{PROCEDURES}

As stated earlier in this report, this research pertains only to whether the proposed modified seasonal factors could be used to improve accuracy in forecasting. The calculation of seasonal factors from the historical data was assumed to be done by traditional methods. The commonly used Holt-Winters trend seasonal forecasting model and Gardner's damped trend multiplicative seasonal model, as well as the ratio-to-moving average method, were selected to produce seasonal indexes for the series used in this study. The proposed modification was then applied to each seasonal index to generate a set of new forecasts. Comparisons were made to the calculated mean absolute percent errors (MAPE), mean errors (ME), mean absolute errors (MAE), and root mean squared errors (RMSE) for each forecasting method.

For a given time series $X_{1}, X_{2}, \ldots, X_{t-1}, X_{n}$ the $m$-step ahead forecast from the Holt-Winters trend seasonal forecasting model is given by

$$
X_{1}(m)=\left(L_{m}+m T_{1}\right) S_{1-p+m},
$$

where

$$
\begin{aligned}
& \mathrm{L}_{1}=\alpha\left(\mathrm{X}_{1} / \mathrm{S}_{1 \cdot \mathrm{p}}\right) *(1-\alpha)\left(\mathrm{L}_{1 \cdot 1}+\mathrm{T}_{1 \cdot 1}\right), \\
& \mathrm{T}_{1}=\theta\left(\mathrm{L}_{1}-\mathrm{L}_{1 \cdot 1}\right)+(1-\theta) \mathrm{T}_{\mathrm{t}-1}, \\
& \mathrm{~S}_{1}=\delta\left(\mathrm{X}_{1} / \mathrm{L}_{1}\right)+(1-\delta) \mathrm{S}_{\mathrm{t} \cdot \mathrm{p}}, \\
& \mathrm{p}=\text { number of periods in cycle, and } \\
& \mathrm{m}=1,2, \ldots, \mathrm{p},
\end{aligned}
$$

for

$$
0 \leq \alpha, \theta, \delta \leq 1 .
$$

Here $L_{r} T_{r}$ and $S_{1}$ represent the smoothed level, smoothed trend, and smoothed seasonal index or factor, respectively, at the end of period $t . X_{1}(m)$ denotes the forecast for $m$ periods ahead from origin $t$. 
By introducing an additional parameter, $\phi$, to modify the trend estimate, Gardner (1985) suggested the use of a damped trend multiplicative seasonal model:

$$
\begin{aligned}
& \mathrm{L}_{1}=\alpha\left(\mathrm{X}_{1} / \mathrm{S}_{\mathrm{t}-\mathrm{p}}\right) *(1-\alpha)\left(\mathrm{L}_{1-1}+\phi \mathrm{T}_{\mathrm{t}-1}\right), \\
& \mathrm{T}_{1}=\theta\left(\mathrm{L}_{1}-\mathrm{L}_{1-1}\right)+(1-\theta) \phi \mathrm{T}_{\mathrm{t}-1}, \\
& \mathrm{~S}_{\mathrm{t}}=\delta\left(\mathrm{X}_{1} / \mathrm{L}_{1}\right)+(1-\delta) \mathrm{S}_{\mathrm{t}-\mathrm{p}},
\end{aligned}
$$

so that the m-step-ahead forecast is estimated by

$$
X_{t}(m)=\left(L_{t}+\sum_{i=1}^{m} \phi^{i} T_{t}\right) S_{t-p+m}
$$

By letting $e_{1}=X_{1}-X_{1.1}, \beta_{1}=\alpha, \beta_{2}=\alpha \theta$, and $\beta_{3}=(1-\alpha) \delta$, the first three equations in Gardner's model are simplified as:

$$
\begin{aligned}
& L_{1}=L_{1-1}+\phi T_{t-1}+\beta_{1} e_{t} / S_{t-p}, \\
& T_{1}=\phi T_{1 \cdot 1}+\beta_{2} e_{1} / S_{1 \cdot p} \text {, } \\
& S_{1}=\beta_{3} e_{1} / L_{1}+S_{1-p} \text {. }
\end{aligned}
$$

The seasonal index $\mathrm{S}_{\mathrm{j}}$ obtained from the above models was then used in the proposed method to produce the modified seasonal factor $S_{j}$,

$$
S_{j}^{\prime}=M_{b}+\left(1-M_{b}\right) S_{j}
$$

A new forecast was then generated from the modified seasonal factor in its usual way. For simplicity, unless otherwise specified, this study generally considered only the one-step-ahead forecasting (i.e., $\mathrm{m}=1$ ) model. 
Two commercially available forecasting PC software packages, AutoCast and $4 \mathrm{CaST} / 2,{ }^{2}$ were used in this research to eliminate computational time required in obtaining seasonal indices for each model. AutoCast provides options for performing Gardner's extrapolating damped trends with seasonality while 4CaST/2 supplies techniques such as Holt-Winters seasonal smoothing, ratio-to-moving average, and census X-11 seasonal adjustment. Due to the complexity of X-11, comparisons between the proposed modified seasonal factors and the $\mathrm{X}-11$ seasonal adjustment were not performed.

An initial evaluation on the Holt-Winters and Gardner's forecasting models, using some of the USN enlisted time series, was conducted during the early stage of this research. Two error measurements, MAPE and RMSE, were employed to compare accuracies of these two methods in the ten-year forecasting horizon. Gardner's model consistently outperforms the Holt-Winters method in all five test series (see Table 2). The decision was then made to put emphasis on the comparisons of forecasting accuracies between Gardner's method and the proposed method. The Holt-Winters model and the ratio-to-moving average method were performed as secondary alternatives.

\footnotetext{
${ }^{2}$ AutoCast (1988) by Everette Gardner and 4CaST/2 (1988) by Heurix, Inc., are products of Levenbach Associates, Inc., 103 Washington Street, \#348, Morristown, NJ 07960.
} 
Table 2. A comparison of the Gardner and Holt-Winters methods in five test series; ten-year forecasting

(fitted period: 1957Q1-1978Q2)

\begin{tabular}{lcccc}
\hline & MAPE & & RMSE & \\
\cline { 4 - 5 } Series & H-W & $G$ & H-W & $G$ \\
\hline E1 & 13.60 & 10.78 & 5389.3 & 4657.9 \\
E3 & 7.20 & 7.03 & 7704.9 & 6563.7 \\
E4 & 7.80 & 4.70 & 7658.7 & 5618.6 \\
E8 $^{\text {b }}$ & 5.29 & 2.80 & 596.1 & 315.4 \\
E9 $^{\text {b }}$ & 8.91 & 3.10 & 402.7 & 137.8 \\
\hline
\end{tabular}

' $\mathrm{H}-\mathrm{W}=$ Holt-Winters method; $\mathrm{G}=$ Gardner's method.

bStarted from the first quarter of 1959. 


\section{RESULTS AND DISCUSSION}

Extensive efforts were directed at the search for the "best" values for $\gamma$ and $\lambda$ used in computing $M_{b}$. "Best" means the parameter value that generates the lowest forecasting error. Various values for $\gamma$ (ranging from 0.1 to 0.8 ) and $\lambda$ (ranging from 0 to 0.5 ) were selected to compute the modifiers. These modifiers were then applied to seasonal indices obtained from Gardner's model (produced by the AutoCast system). Error estimates for the nine individual USN paygrade series, as well as their averages (arithmetic mean) and geomeans (geometric mean) were compared. Tables 3-5 present summaries of MAPE comparisons for $\gamma=0.2,0.5$, and 0.7 , respectively. Forecasting errors estimated using Naive-3 models are also shown in these tables.

For all cases, both Gardner's damped trend seasonal model and the proposed modified seasonal factors outperform the Naive-3 model. The proposed model improved forecasting accuracy (from Gardner's seasonal indices) for series E1, E5, E7, E8, and E9 in all three tables for all $\lambda$ values used. Comparisons among other series (E2, E3, E4, and E6) show a dependency on the values of $\lambda$ chosen. Regardless of the use of modified or unmodified (Gardner's) seasonal factors in a forecasting model, the estimated ten-year forecasting MAPE for the higher paygrades (E5 and above) are generally smaller (2-3\%).

Forecasting for E1 had the highest error among all series. This might be due to the nature of Navy force structures in which the lower paygrade series do not seem to be as stable as the higher ranking paygrade series. The inventory numbers in the lower paygrades are generally larger and subject to a larger fluctuation. Further investigation is needed before any conclusions can be drawn about this subject.

In addition to the possible impact of paygrade levels, the parameters $\lambda$ and $\gamma$ also show influence on the degrees of improvements that the modified seasonal factors provide (either positive or negative). The estimated MAPE for paygrade 
Table 3. A summary of MAPE comparisons for $\gamma=0.2$

\begin{tabular}{|c|c|c|c|c|c|c|c|c|c|c|c|}
\hline & E1 & E2 & E3 & E4 & E5 & E6 & E7 & E8 & E9 & avg. & geo.mean \\
\hline $\begin{array}{l}\text { Cardnor } \\
\text { Natwo } 3\end{array}$ & $\begin{array}{l}10.7519 \\
15,6030\end{array}$ & $\begin{array}{l}6.5516 \\
6.8627\end{array}$ & $\begin{array}{l}7.0846 \\
0.5000\end{array}$ & $\begin{array}{l}4.7794 \\
8.5776\end{array}$ & $\begin{array}{l}2.32022 \\
2.0025\end{array}$ & $\begin{array}{l}1,8483 \\
2.0540\end{array}$ & $\begin{array}{l}2.0029 \\
2.3477\end{array}$ & $\begin{array}{l}2.9518 \\
4.8064\end{array}$ & $\begin{array}{l}2.7961 \\
6.2842\end{array}$ & $\begin{array}{l}4.5688 \\
6.5644\end{array}$ & $\begin{array}{l}3.8209 \\
5.3861\end{array}$ \\
\hline
\end{tabular}

Lambda (Gamma=.2)

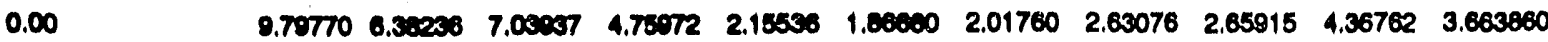

$\begin{array}{llllllllllll}0.05 & 0.74001 & 6.35668 & 7.04000 & 4.76000 & 2.14068 & 1.86761 & 2.01669 & 2.61398 & 2.65255 & 4.35731 & 3.656533\end{array}$

$\begin{array}{lllllllllllll}0.10 & 0.60795 & 6.34484 & 7.06312 & 4.77862 & 2.14300 & 1.86863 & 2.01687 & 2.60978 & 2.64543 & 4.35192 & 3.652704\end{array}$

$\begin{array}{lllllllllllll}0.15 & 0.65005 & 6.40022 & 7.06097 & 4.70005 & 2.14035 & 1.00986 & 2.01516 & 2.61449 & 2.64104 & 4.35839 & 3.657079\end{array}$

$\begin{array}{lllllllllllll}0.20 & 0.63005 & 6.40200 & 7.12243 & 4.60200 & 2.13833 & 1.87070 & 2.01457 & 2.63074 & 2.64104 & 4.37119 & 3.666178\end{array}$

$\begin{array}{llllllllllll}0.26 & 9.62921 & 6.50050 & 7.16500 & 4.82676 & 2.13500 & 1.87175 & 2.01416 & 2.65076 & 2.64122 & 4.39280 & 3.680483\end{array}$

$\begin{array}{lllllllllllll}0.30 & 9.60006 & 6.74009 & 7.20400 & 4.86636 & 2.13500 & 1.86854 & 2.01035 & 2.65999 & 2.63968 & 4.41310 & 3.692360\end{array}$

$\begin{array}{llllllllllll}0.35 & 0.57017 & 6.05835 & 7.23170 & 4.06714 & 2.14147 & 1.87836 & 2.00192 & 2.66312 & 2.64134 & 4.42596 & 3.701635\end{array}$

$\begin{array}{lllllllllllll}0.40 & 0.63462 & 6.80040 & 7.24140 & 4.80010 & 2.16180 & 1.83354 & 1.89972 & 2.65970 & 2.63774 & 4.44094 & 3.709831\end{array}$

$\begin{array}{llllllllllll}0.45 & 0.67899 & 6.82101 & 7.24446 & 4.607702 & 2.15680 & 1.88496 & 1.99739 & 2.65716 & 2.63262 & 4.44904 & 3.713212\end{array}$

$\begin{array}{llllllllllll}0.50 & 9.66870 & 6.93046 & 7.24470 & 4.06473 & 2.15827 & 1.82500 & 1.89630 & 2.65473 & 2.62658 & 4.44750 & 3.711735\end{array}$

Table 4. A summary of MAPE comparisons for $\gamma=0.5$

$\begin{array}{llllllllllll} & \text { E1 } & \text { E2 } & \text { E3 } & \text { E4 } & \text { ES } & \text { E6 } & \text { E7 } & \text { E8 } & \text { E9 } & \text { avg. } & \text { goo.mean } \\ \text { Cardnor } & 10.7519 & 6.5516 & 7.0546 & 4.7794 & 2.3220 & 1.8463 & 2.0629 & 2.8518 & 2.7961 & 4.5688 & 3.8209 \\ \text { Natvo 3 } & 15.503 & 6.0527 & 0.5000 & 6.5776 & 2.0625 & 2.0540 & 2.3477 & 4.8064 & 6.2842 & 6.5644 & 5.3861\end{array}$

Lamboda (Gamma=.5)

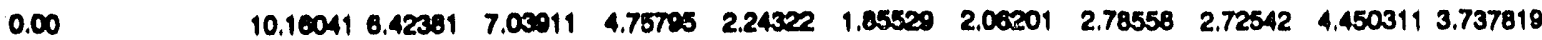

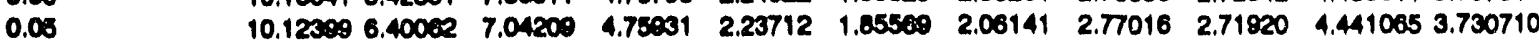

$\begin{array}{llllllllllll}0.10 & 10.08431 & 6.37428 & 7.04531 & 4.78245 & 2.23036 & 1.85610 & 2.00034 & 2.75479 & 2.71244 & 4.431206 & 3.723227\end{array}$

$\begin{array}{llllllllllll}0.15 & 10.04106 & 6.34434 & 7.04076 & 4.76084 & 2.20288 & 1.05851 & 2.00030 & 2.73884 & 2.70506 & 4.420514 & 3.715163\end{array}$

$\begin{array}{lllllllllllll}0.20 & 0.00369 & 6.31040 & 7.05284 & 4.77168 & 2.21400 & 1.85002 & 2.05691 & 2.72141 & 2.69707 & 4.408702 & 3.706247\end{array}$

$\begin{array}{llllllllllll}0.25 & 0.04756 & 6.27197 & 7.05661 & 4.77701 & 2.20542 & 1.05734 & 2.05037 & 2.70236 & 2.69096 & 4.396513 & 3.696996\end{array}$

$\begin{array}{lllllllllllll}0.30 & 0.00057 & 6.23720 & 7.06100 & 4.70287 & 2.19526 & 1.05776 & 2.05601 & 2.08157 & 2.68698 & 4.384477 & 3.687803\end{array}$

$\begin{array}{llllllllllll}0.30 & 0.04465 & 6.21251 & 7.06578 & 4.70832 & 2.16014 & 1.05810 & 2.05873 & 2.68048 & 2.68265 & 4.373380 & 3.679582\end{array}$

$\begin{array}{llllllllllll}0.40 & 9.78532 & 6.18410 & 7.07001 & 4.70041 & 2.10103 & 1.05050 & 2.05875 & 2.63729 & 2.67795 & 4.361153 & 3.670623\end{array}$

$\begin{array}{llllllllllll}0.45 & 0.72001 & 6.15100 & 7.07040 & 4.00420 & 2.17528 & 1.05800 & 2.05002 & 2.61180 & 2.67285 & 4.347802 & 3.681055\end{array}$

$\begin{array}{llllllllllll}0.50 & 0.67271 & 6.11446 & 7.00060 & 4.81277 & 2.16876 & 1.85039 & 2.05046 & 2.59503 & 2.66732 & 4.337401 & 3.653422\end{array}$

Table 5. A summary of MAPE comparisons for $\gamma=0.7$

\begin{tabular}{|c|c|c|c|c|c|c|c|c|c|c|c|}
\hline & E1 & E2 & E3 & E4 & E5 & E6 & E7 & E8 & E9 & avg. & geo.moan \\
\hline $\begin{array}{l}\text { Cardnor } \\
\text { Natro } 3\end{array}$ & $\begin{array}{l}10.7519 \\
15.603\end{array}$ & $\begin{array}{l}6.0516 \\
6.8527\end{array}$ & $\begin{array}{l}7.0646 \\
0.00000\end{array}$ & $\begin{array}{l}4.7794 \\
8.5778\end{array}$ & $\begin{array}{l}2.3222 \\
2.00255\end{array}$ & $\begin{array}{l}1.0403 \\
2.0540\end{array}$ & $\begin{array}{l}2.0829 \\
2.3477\end{array}$ & $\begin{array}{l}2.8518 \\
4.8064\end{array}$ & $\begin{array}{l}2.7961 \\
6.2842\end{array}$ & $\begin{array}{l}4.5688 \\
6.5644\end{array}$ & $\begin{array}{l}3.8209 \\
5.3861\end{array}$ \\
\hline
\end{tabular}

Lambda (Gamma=.n)

\begin{tabular}{|c|c|c|c|c|c|c|c|c|c|}
\hline $\begin{array}{l}0.00 \\
0.05\end{array}$ & $\begin{array}{l}10.305020 .40405 \\
10.350046 .45200\end{array}$ & $\begin{array}{l}7.05974 \\
7.04006\end{array}$ & $\begin{array}{l}4.70000 \\
4.76606\end{array}$ & $\begin{array}{l}2.27043 \\
2.27513\end{array}$ & $\begin{array}{l}1.86242 \\
1.85255\end{array}$ & $\begin{array}{l}2.07799 \\
2.07786\end{array}$ & $\begin{array}{l}2.80003 \\
2.85152\end{array}$ & $\begin{array}{l}2.75708 \\
2.75365\end{array}$ & $\begin{array}{l}4.4970983 .775153 \\
4.4922053 .771107\end{array}$ \\
\hline .10 & 10.334916 .43762 & 7.04230 & 4.76747 & 2.27147 & 1.85268 & 2.07735 & 2.84224 & 2.74991 & 4.4662483 .766700 \\
\hline 1 & 10.307756 .4 & 7.04427 & 4.76834 & .26742 & 1.85280 & 2.07708 & 2.83210 & 2.74585 & 4.4786903 .701843 \\
\hline 20 & 10.278256 .40325 & 7.04630 & 4.70020 & 2.20294 & 1.852808 & 2.07679 & 2.82104 & 2.74143 & 3.756492 \\
\hline 0.25 & 10.246216 .30244 & 7.04051 & 4.77032 & 2.25797 & 1,65302 & 2.07656 & 2.80696 & 2.73661 & 4.464511 \\
\hline 0.30 & 10.211376 .35000 & 7.06000 & 4.77144 & $2.2524 y^{\prime}$ & 1.8 & 2.07836 & 2.79576 & 2.73137 & 4.4557 \\
\hline 0.35 & $10.17403 \quad 6.33227$ & 7.05346 & 4.77204 & 2.24637 & 1.8 & 2.07621 & 2.78132 & 2.72566 & 4.44810 \\
\hline 0.40 & 10.137746 .30220 & 7.00020 & 4.77588 & 2.23902 & 1.8 & 2.07612 & 2.76668 & 2.71943 & 4.4363 \\
\hline 0.46 & 10.00008 & 7.00027 & 4.76000 & 2.23213 & 1.8 & 2.07600 & 2.75077 & 2.71265 & 4.42 \\
\hline & & & & & & & & & \\
\hline
\end{tabular}


series E1, E3, and E8 with various $\lambda$ and $\gamma$ values are displayed in Appendix A, Figures A.9-A.11. Corresponding RMSE plots are shown in Figures A.12-A.14. By examining results obtained from this investigation, it seems that no single pair of "optimal" $(\lambda, \gamma)$ values existed that could provide a common set of modifiers for all NPRDC series. In general, a small value of $\lambda$ and a $\gamma$ value in the range of 0.20.3 provides reasonable results for all series in this study.

A similar but very limited investigation on the LOS series (i.e., summary data broken down by IOOS) was carried out to examine the concept of modified seasonal factors. Among the 31 time series (LOS 1-31), under different combinations of $\lambda$ and $\gamma$, the modified seasonal factors outperformed (i.e., with a smaller MAPE) the Gardner's damped trend seasonal model for about 16 series. The differences, however, were generally marginal. Unlike the paygrade breakdown series, in which Naive-3 was always the unfavorable forecasting method, four of these LOS break-down series yielded a lower MAPE when Naive-3 was used. Table 6 gives sample results from this examination.

No significant gain in accuracy was achieved from the proposed modified seasonality model. Although the failure may be due to the lack of pronounced seasonal factors in some of these time series, the highly aggregated nature of these series might have also contributed to the problem. There is a strong correlation between paygrade and LOS. Typically a lower LOS corresponds to both a lower paygrade and a larger number of personnel in the NPRDC data. Without further tests on other types of datasets, the usefulness of the proposed method, or a similar concept, cannot be properly determined.

The research indicates that use of modified seasonal factors led to improved accuracy for predictions of inventories by paygrade using quarterly data. The MAPE was reduced by over $4 \%$ in some cases. It is expected that the modified seasonal factors will only be of value for series where the estimated seasonal factors show a substantial variation across the year. 
Table 6. A comparison of the proposed modified seasonal factor, Gardner's, and the Naive-3 models on series LOS $=1-31$ for $\gamma=0.2$

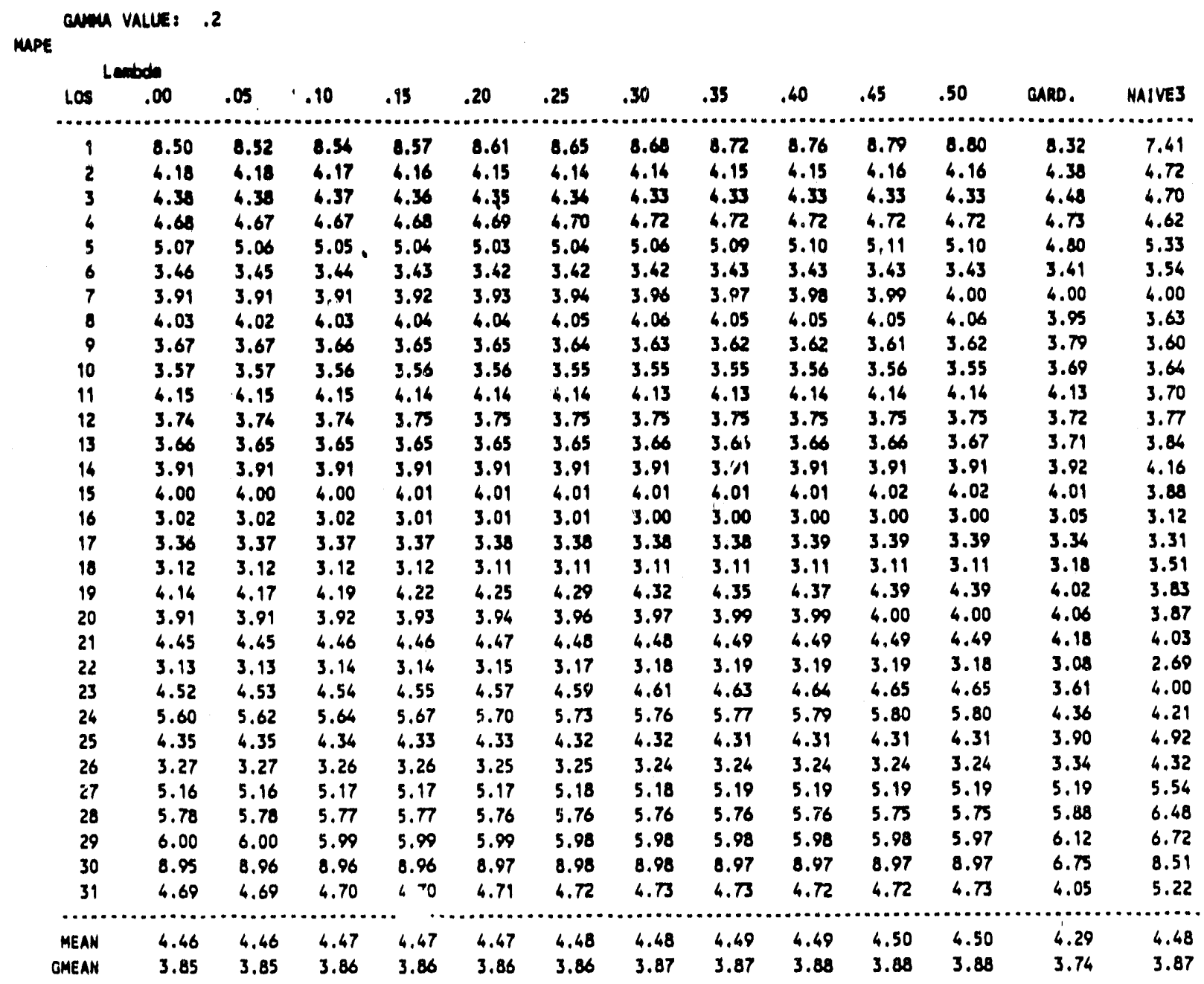




\section{REFERENCES}

Gardner, Everette S., Jr., and E. McKenzie, "Forecasting Trends in Time Series," Management Science, 31, (1985), 1237-1246.

Groff, Gene K., "Empirical Comparison of Models for Short Range Forecasting," Management Science, 20, (1973), 22-31.

Nelson, Charles R., "The Prediction Performance of the FRB-MIT-Penn Model of the U.S. Econorny," American Economic Review, 5, (1972), 902-917. 
APPENDIX A: DATA PLOTS 
Figure A 1

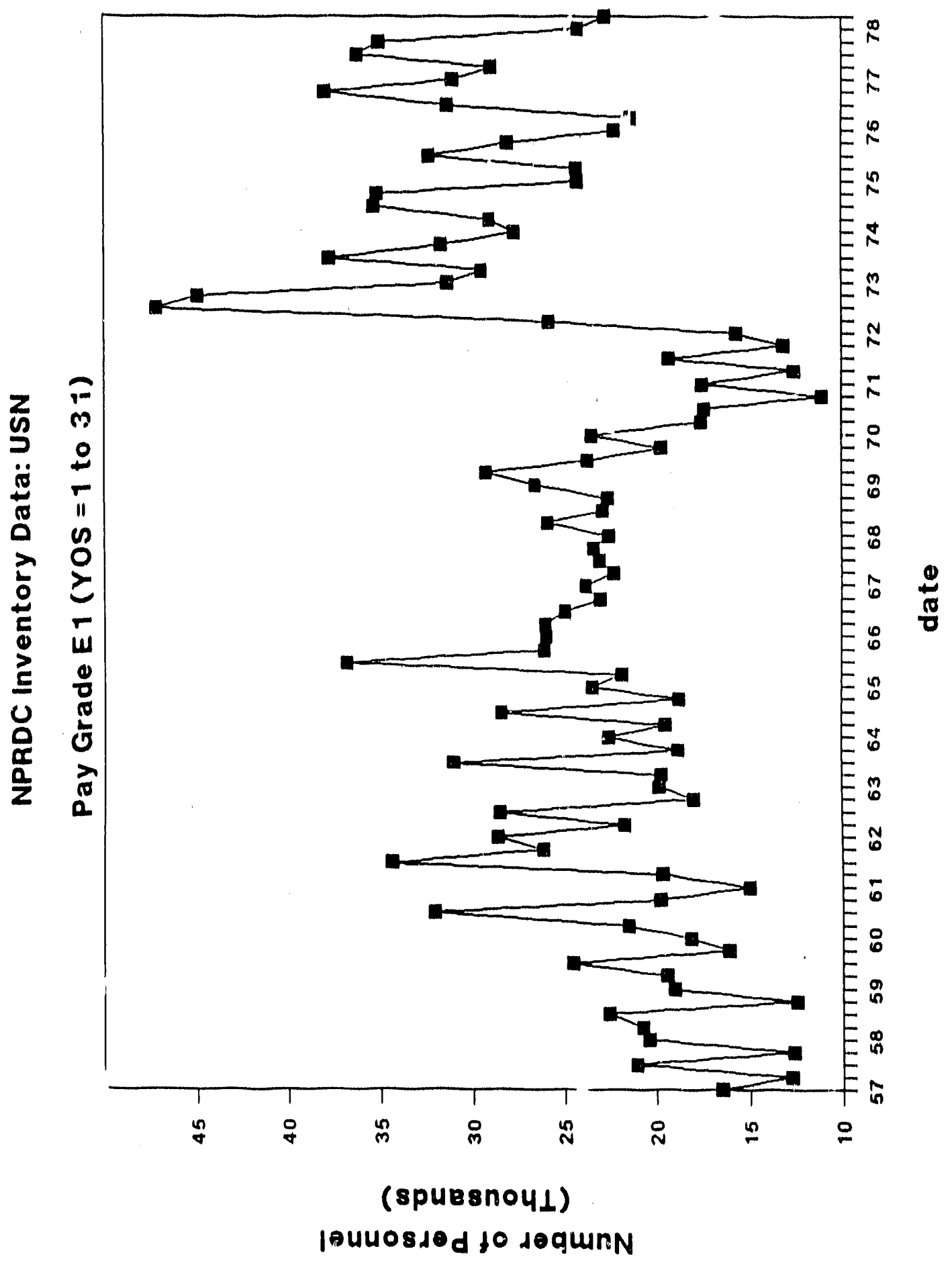

A-3 
Figure A.2

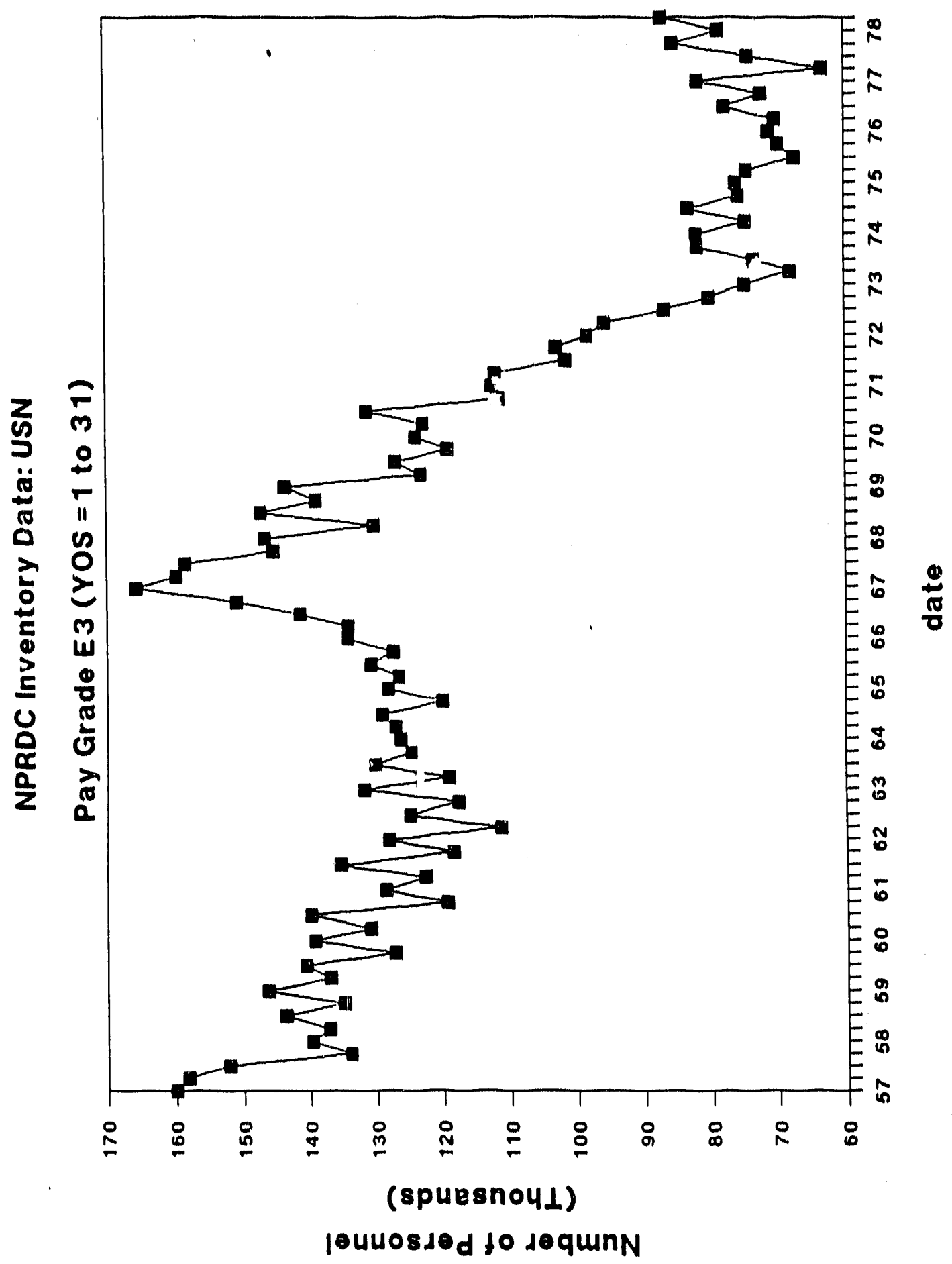


Figure A.3

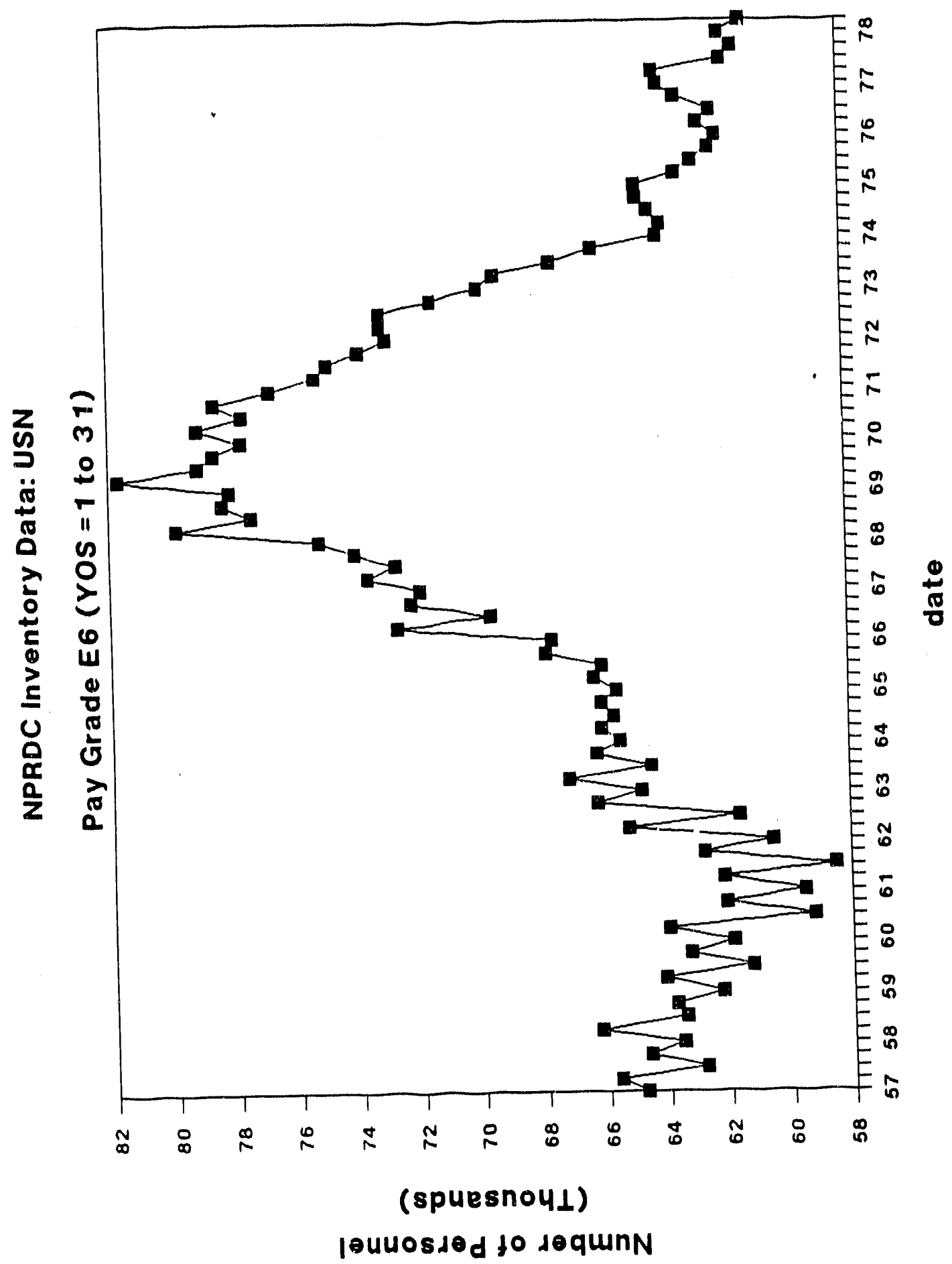

A-5 
Figure A.4

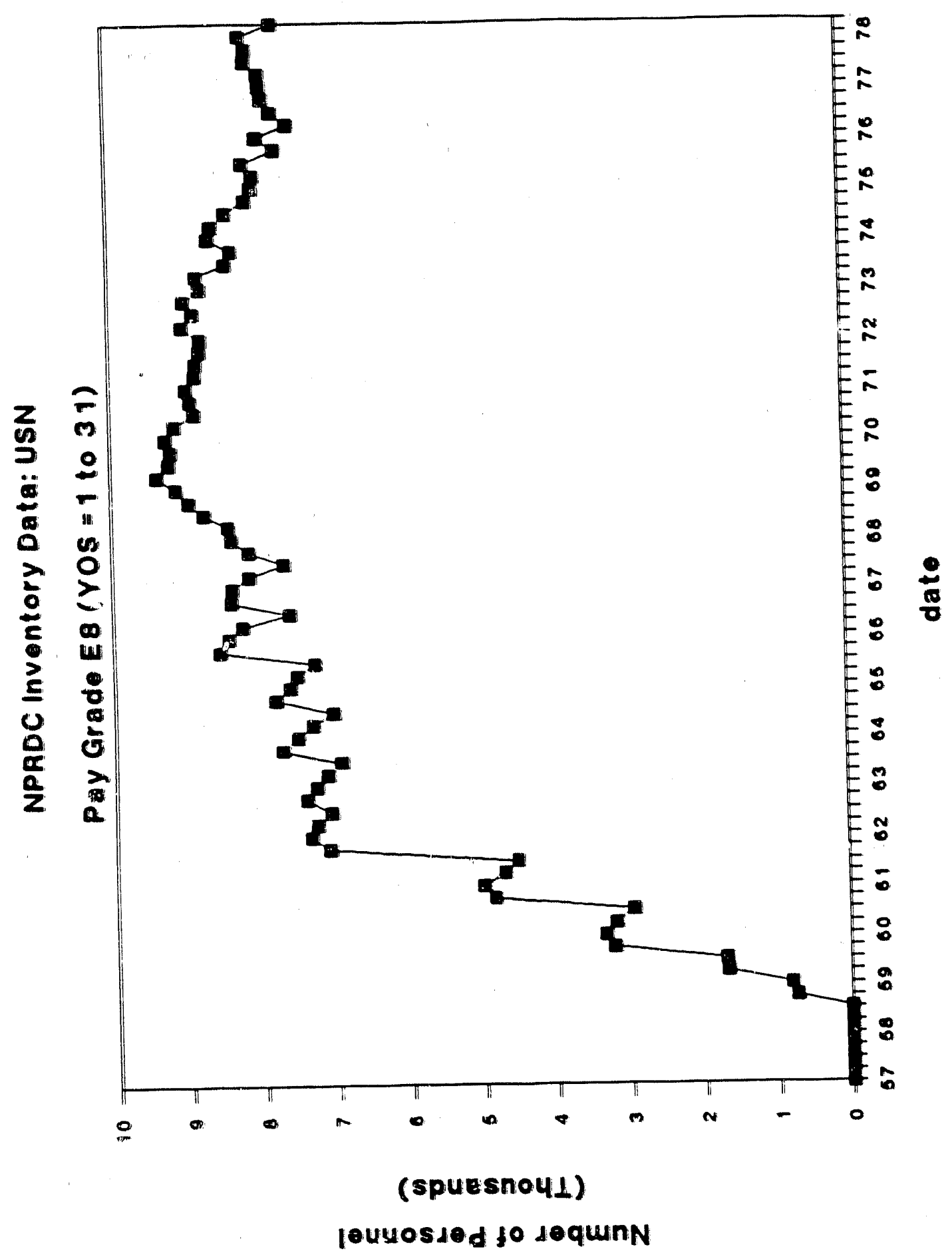

A-6 
Figure A.5

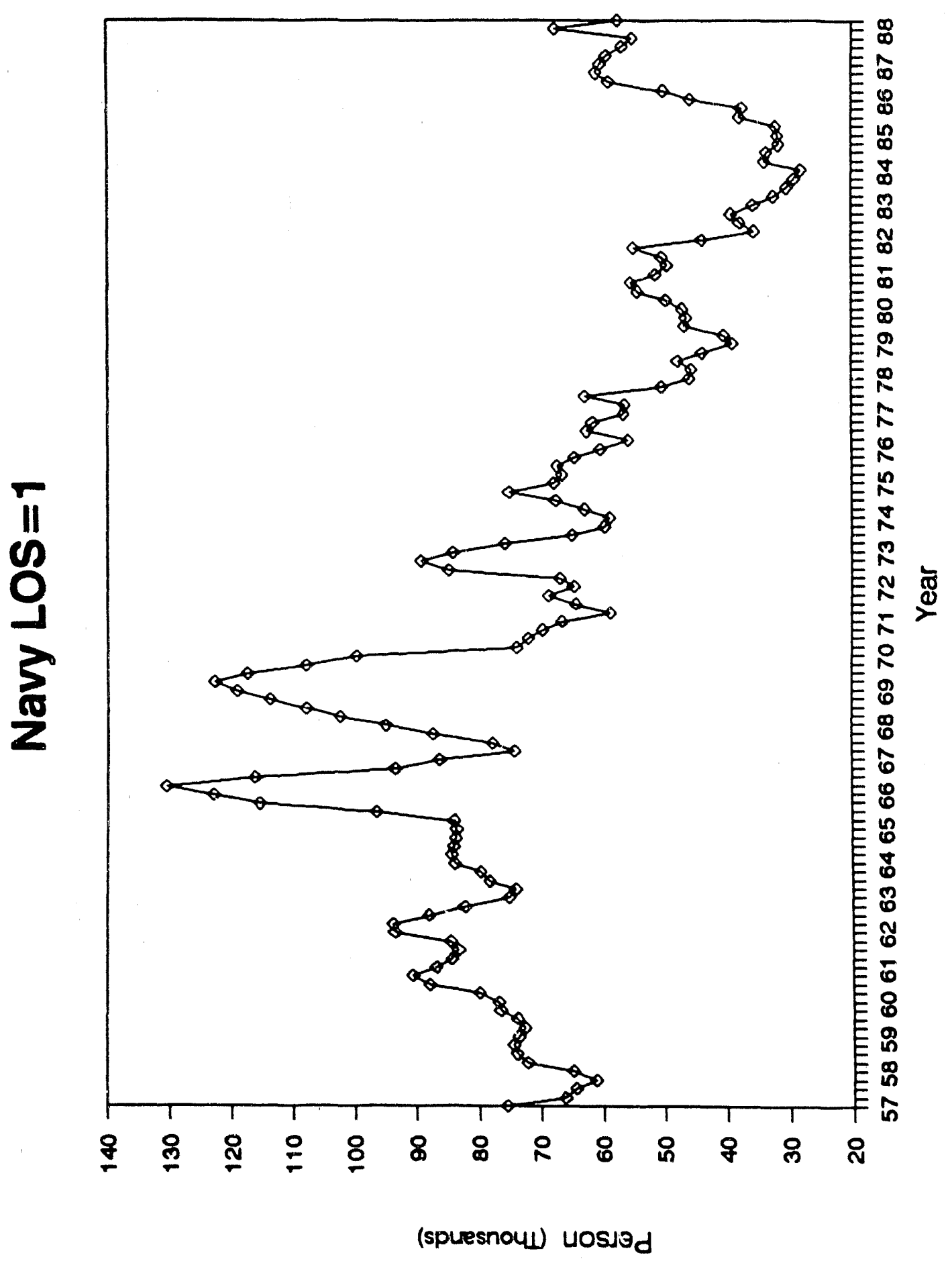

A-7 
Figure A.6

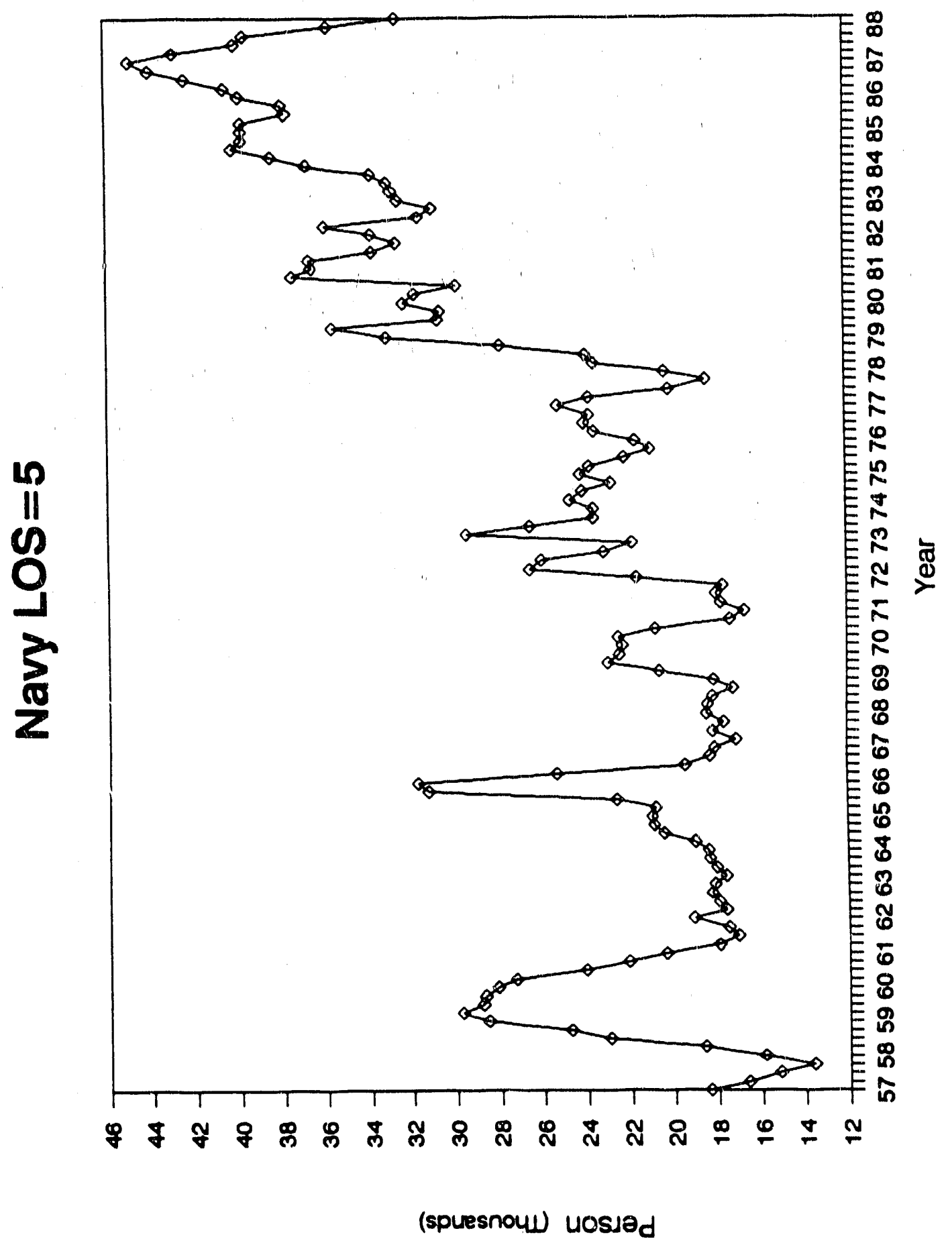

A-8 
Figure A.7

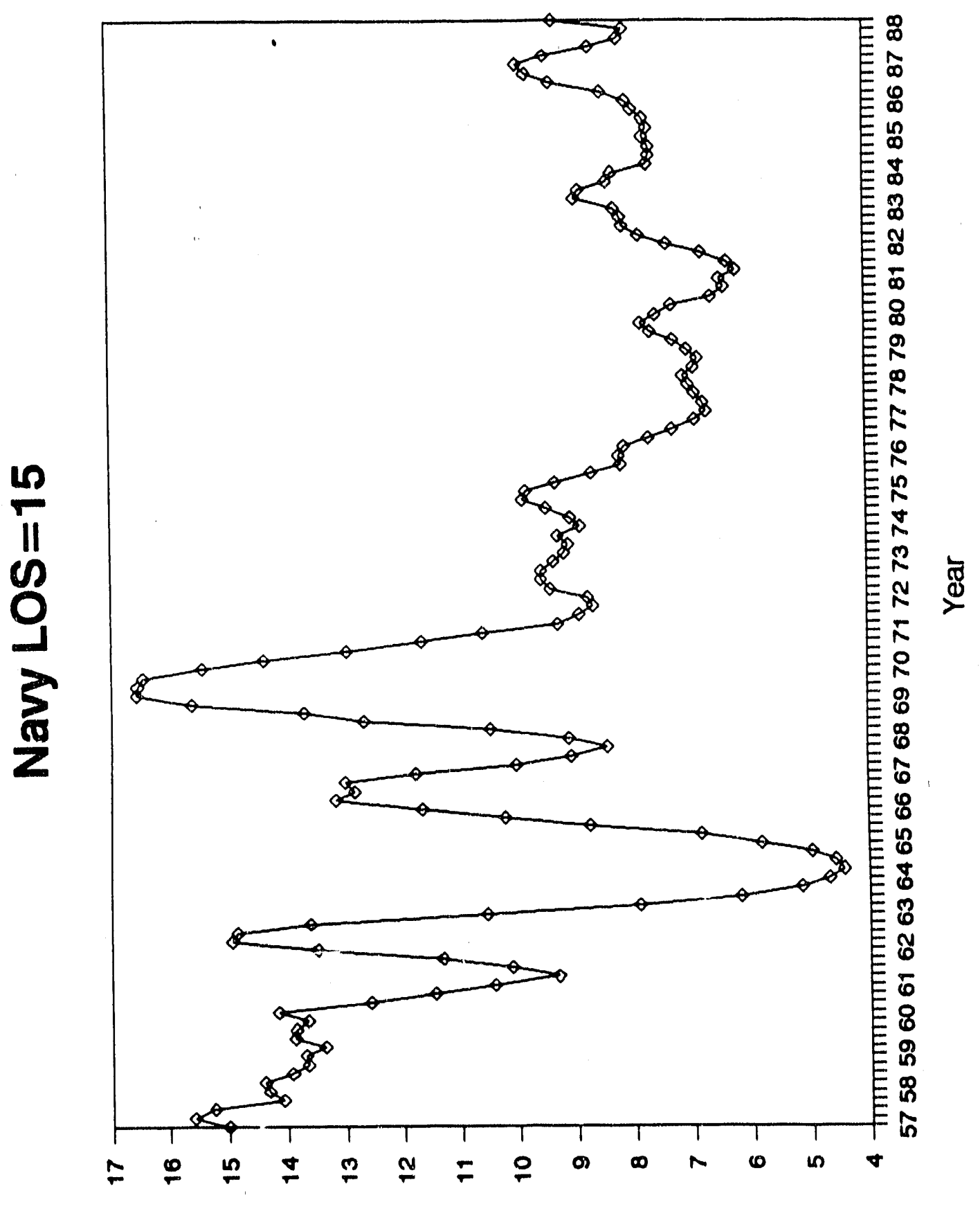

(spuresnoul) uosiod 
Figure A.8

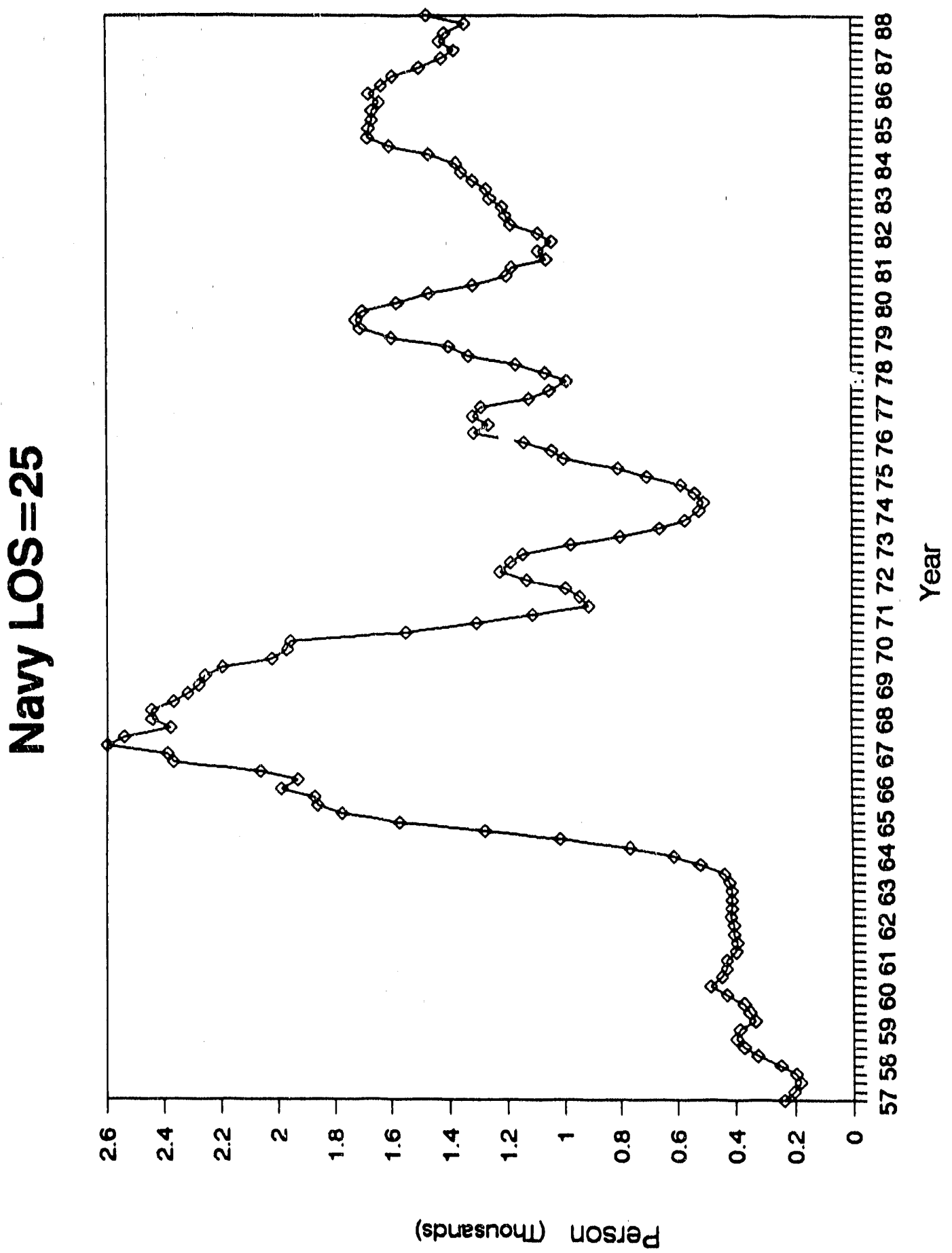


Figure A.9

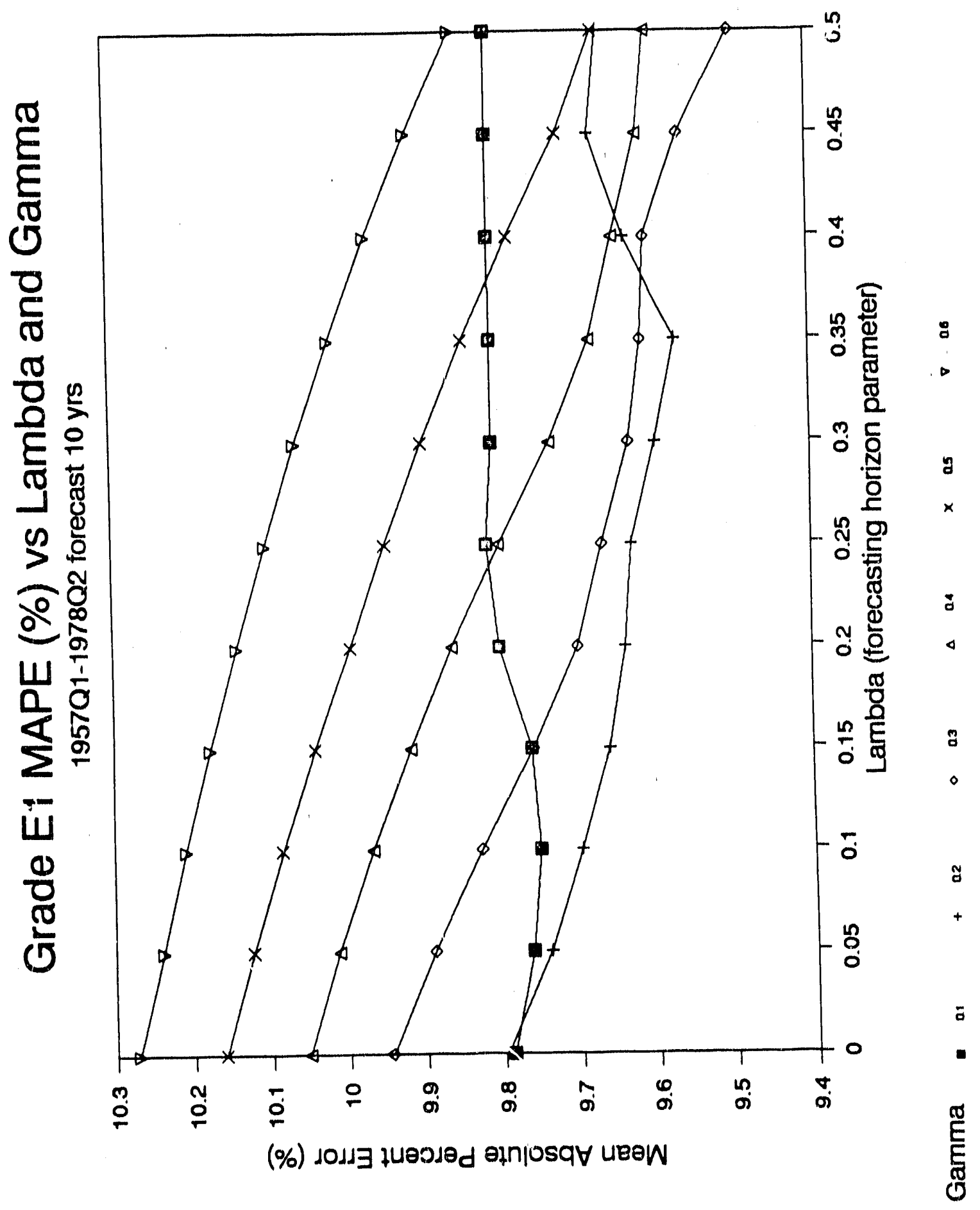


Figure A.10

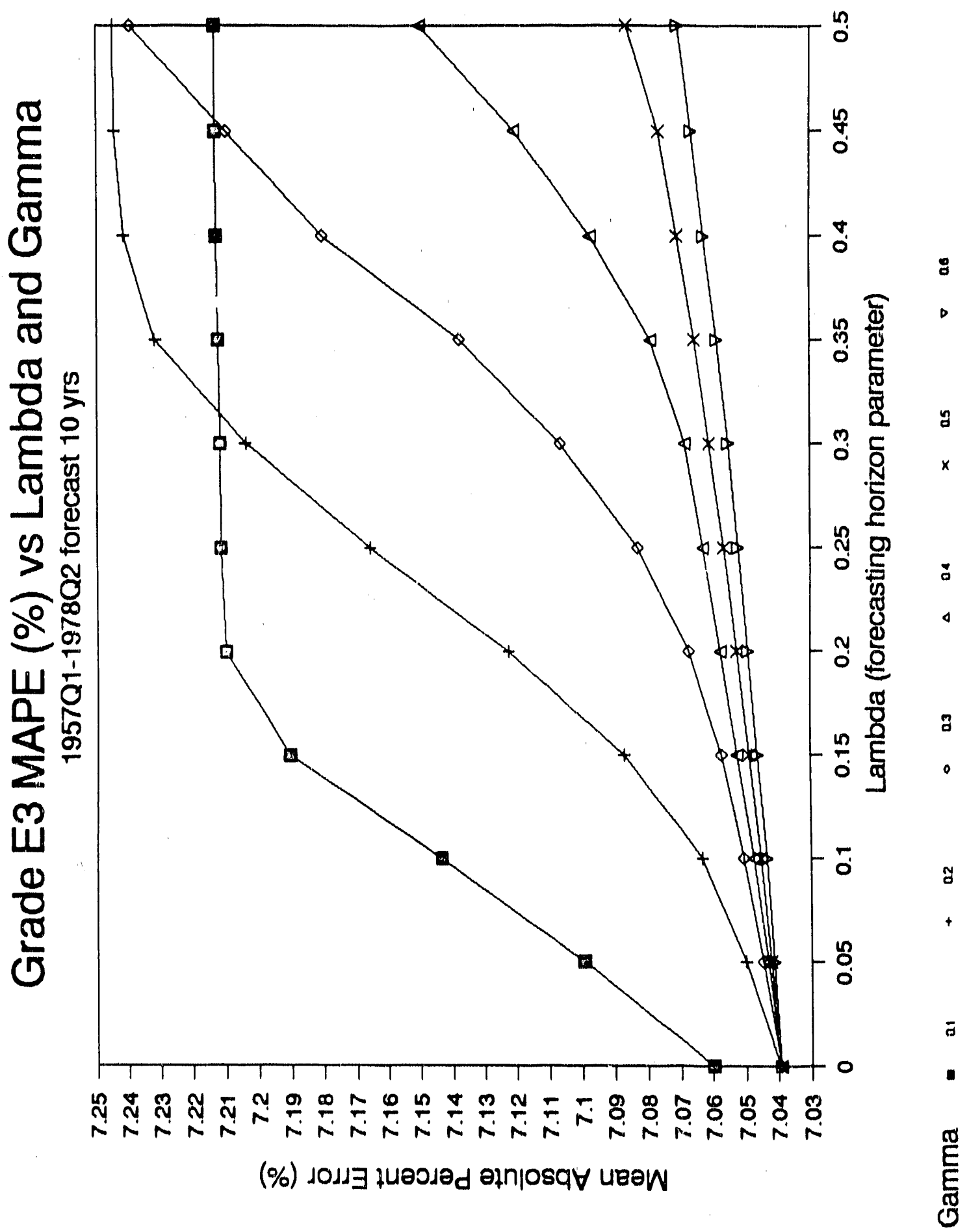


Figure A.11

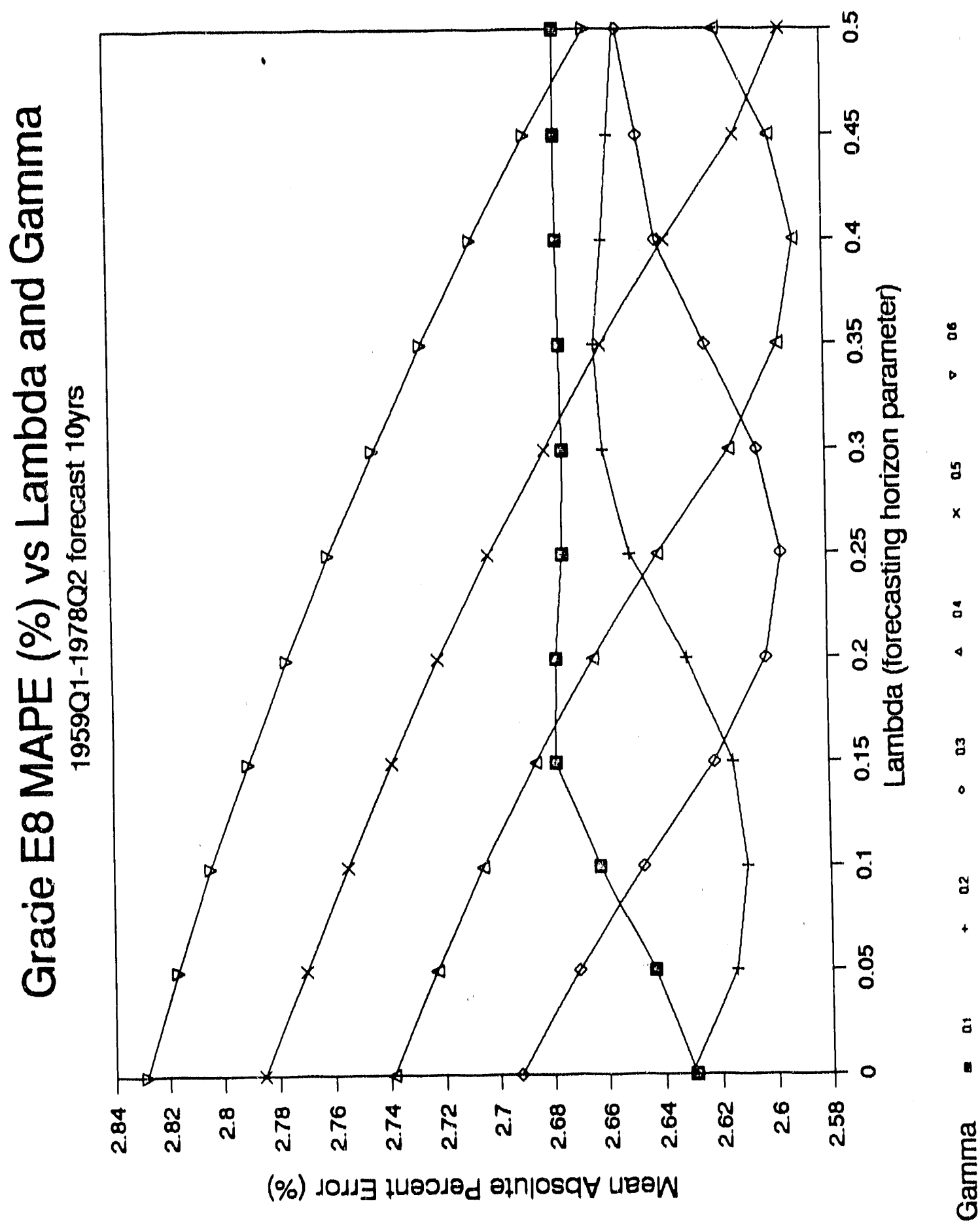


Figure A.12

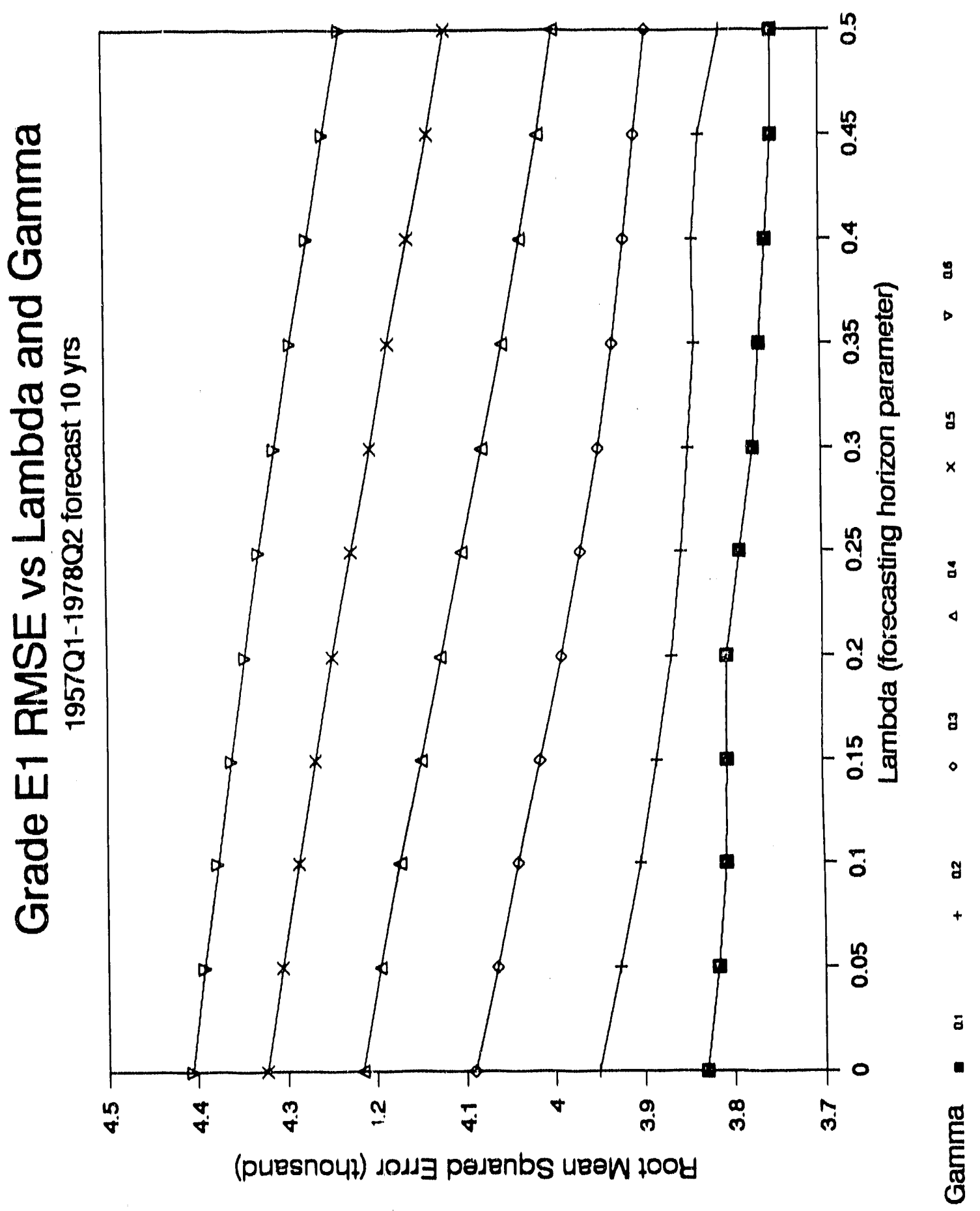


Figure A.13

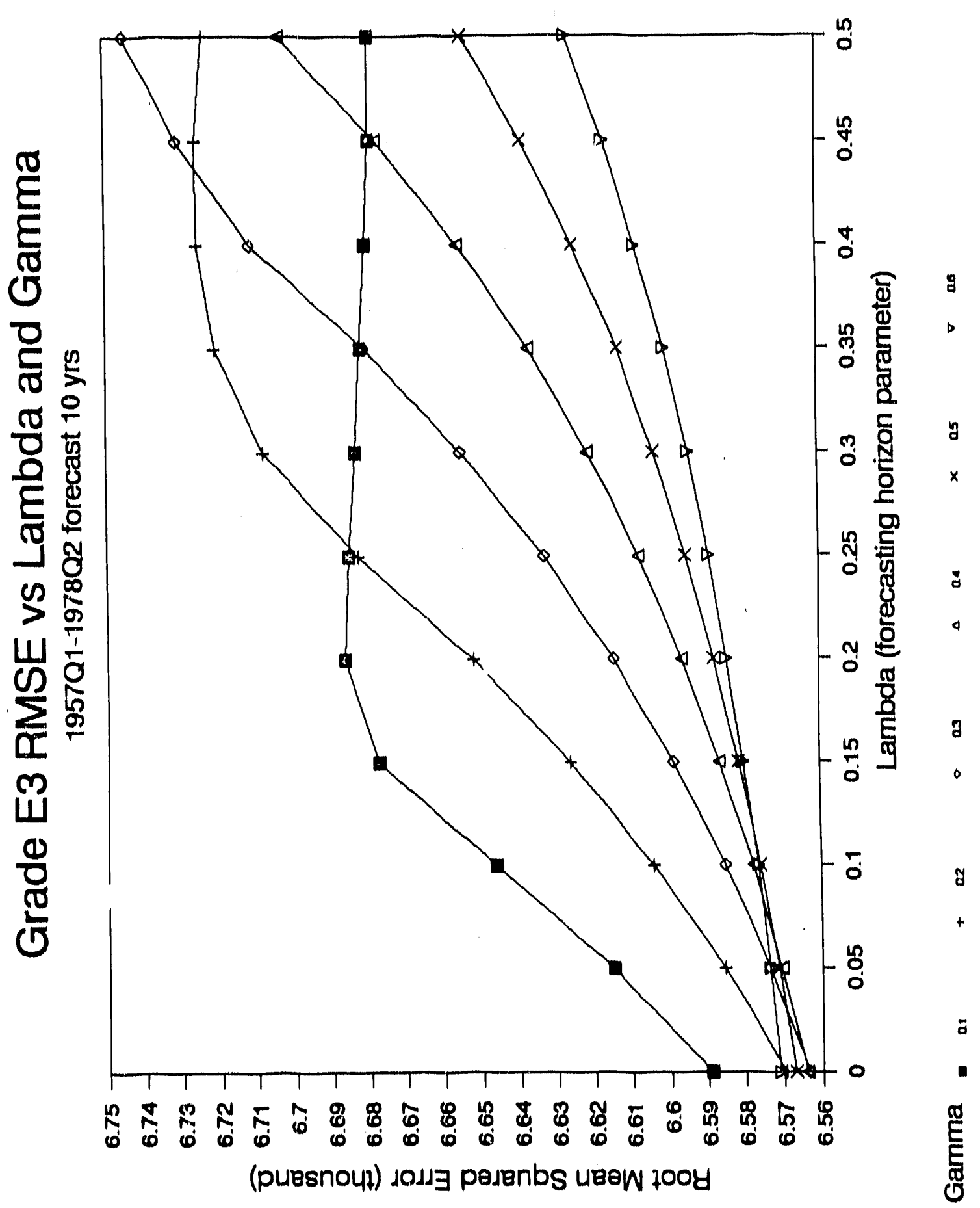


Figure A.14

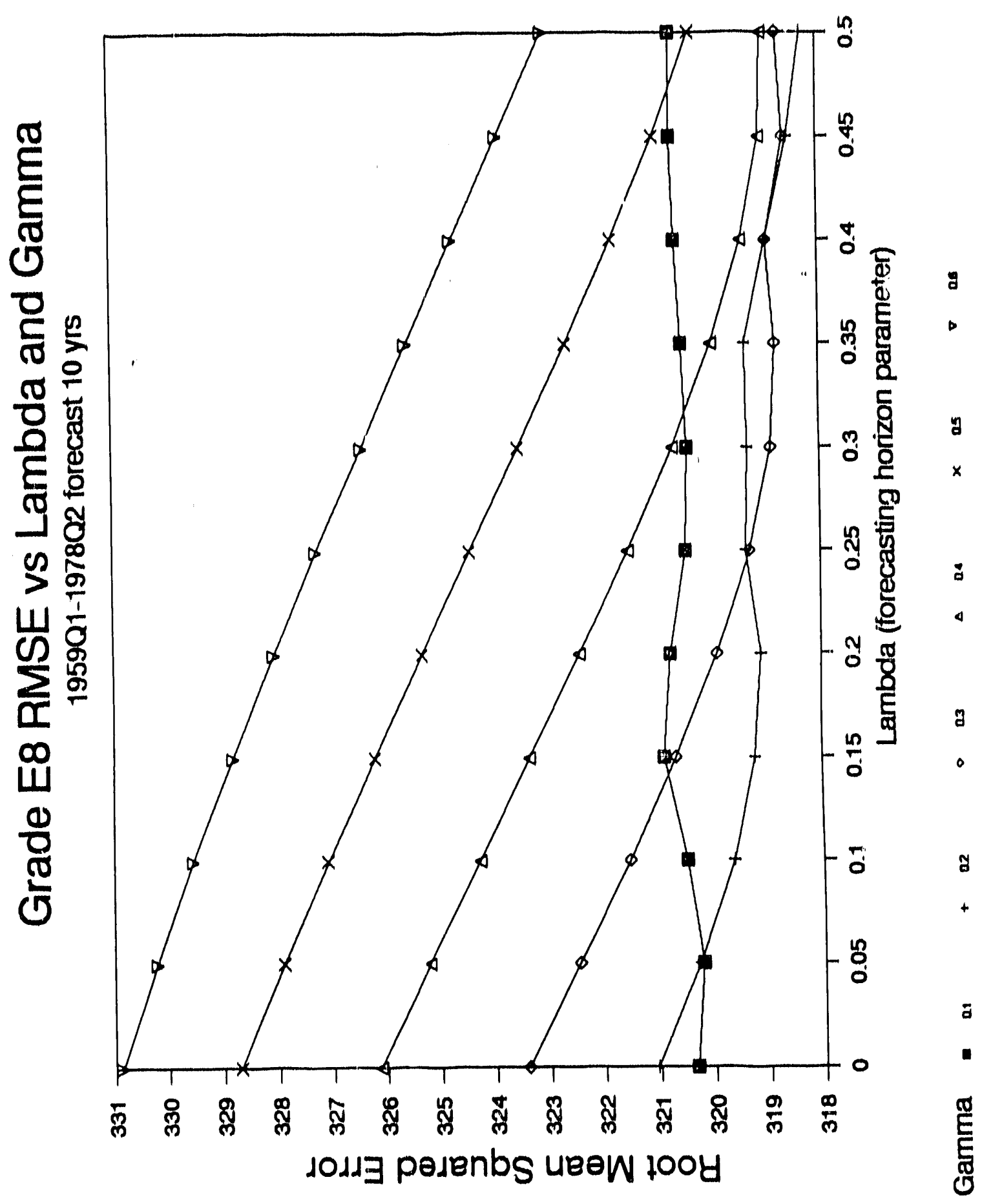




\section{APPENDIX B: USE OF SUBJECTIVE INFORMATION}

The concept of using the subjective information about causality, $d_{a}$, was examined using the following equation:

$$
M_{b} \text { ir } \operatorname{Min}\left\{1,\left(d+d_{d}\right)^{-\gamma *} h^{\lambda}\right\}, \quad \text { for } d \geq 1 \text { and } 0 \leq \gamma, \lambda \leq 1 \text {, }
$$

where $\operatorname{Min}\{a, b\}$ represents the value of $a$ or $b$, whichever is smaller. It was assumed that the subjective information can be quantifled as an integer value from 0 to 3, depending upon the confidence that one might have in the subjective knowledge. For simplicity, an arbitrarily selected value of $\gamma=0.5$ was substituted into the formula. Various values for $\lambda$, ranging from 0 to 0.5 , with a forecast horizon of 10 years were used. These resulting modifiers were then applied to modify seasonal indices obtained from the Gardner's damped trend multiplicative seasonal model. New estimates of errors were computed for each case. With these relatively long series (approximately 21 years) under the study, it was no surprise to find that $d_{d}$ has no significant impact on the forecasting accuracy, Interestingly though, in most cases, forecasting accuracy decreases as the $d_{1}$ value increases. An example is given in Tatle B.1 on time series USN-E1 for $\lambda=0.05,0.1$, and 0.2 . 
Tablo B-1. Modified scasonal factor for E1 paygradc; 10 ycars forccasting (fitted poriod $=1957 \mathrm{Q} 1-1978 \mathrm{Q} 2)$

\begin{tabular}{|c|c|c|c|c|}
\hline \multicolumn{5}{|c|}{ MAPE } \\
\hline$\lambda$ & 0 & 1 & 2 & 3 \\
\hline 0.05 & 10.3043 & 10.3099 & 10.3150 & 10.3196 \\
\hline 0.1 & 10.2756 & 10.2817 & 10.2875 & 10.2928 \\
\hline 0.2 & 10,2156 & 10,1276 & 10.2241 & 10.2308 \\
\hline
\end{tabular}

RMSE

\begin{tabular}{cc|cccc}
$\lambda$ & & $d_{1}$ & \multicolumn{4}{c}{} \\
\hline 0.05 & 0 & 1 & 2 & 3 \\
\hline 0.1 & 4314.44 & 4321.46 & 4328.02 & 4334.14 \\
0.2 & 4299.37 & 4306,54 & 4313.28 & 4319.65 \\
& 4268.88 & 4267.28 & 4283.27 & 4289.84
\end{tabular}

To further investigate the benefit of adding the $d_{d}$ term, several different five-year periods in the original USN E1, E3, and E8 series were extracted to form shorter time series. Figures B.1-B.6 display MAPEs and RMSEs for some of those series that cover the period from the third quarter of 1973 to the second quarter of 1978. In these figures, "p" is the value of the subjective factor $d_{s}$. It can be seen from these figures that the use of a subjective factor, $\mathrm{d}_{\mathrm{s}}$, does not always improve the accuracy of forecasts. In fact, among, all series that were used in this study, only a few series showed improvements in forecasting accuracy. Apparently, the use of a subjective factor was far more complicated than what was anticipated. Further investigations to study the characteristics among the nature of these NPRDC series might need to be conducted before reevaluating the usefulness of the subjective factor.

Therefore, the modified seasonal factor $\mathrm{M}_{\mathrm{b}}$ being considered in the later stage of this study became:

$$
M_{h}=\operatorname{Min}\left\{1, d^{* *} h^{\lambda}\right\}, \text { for } d \geq 1 \text { and } 0 \leq \gamma, \lambda \leq 1
$$


Figure B.1

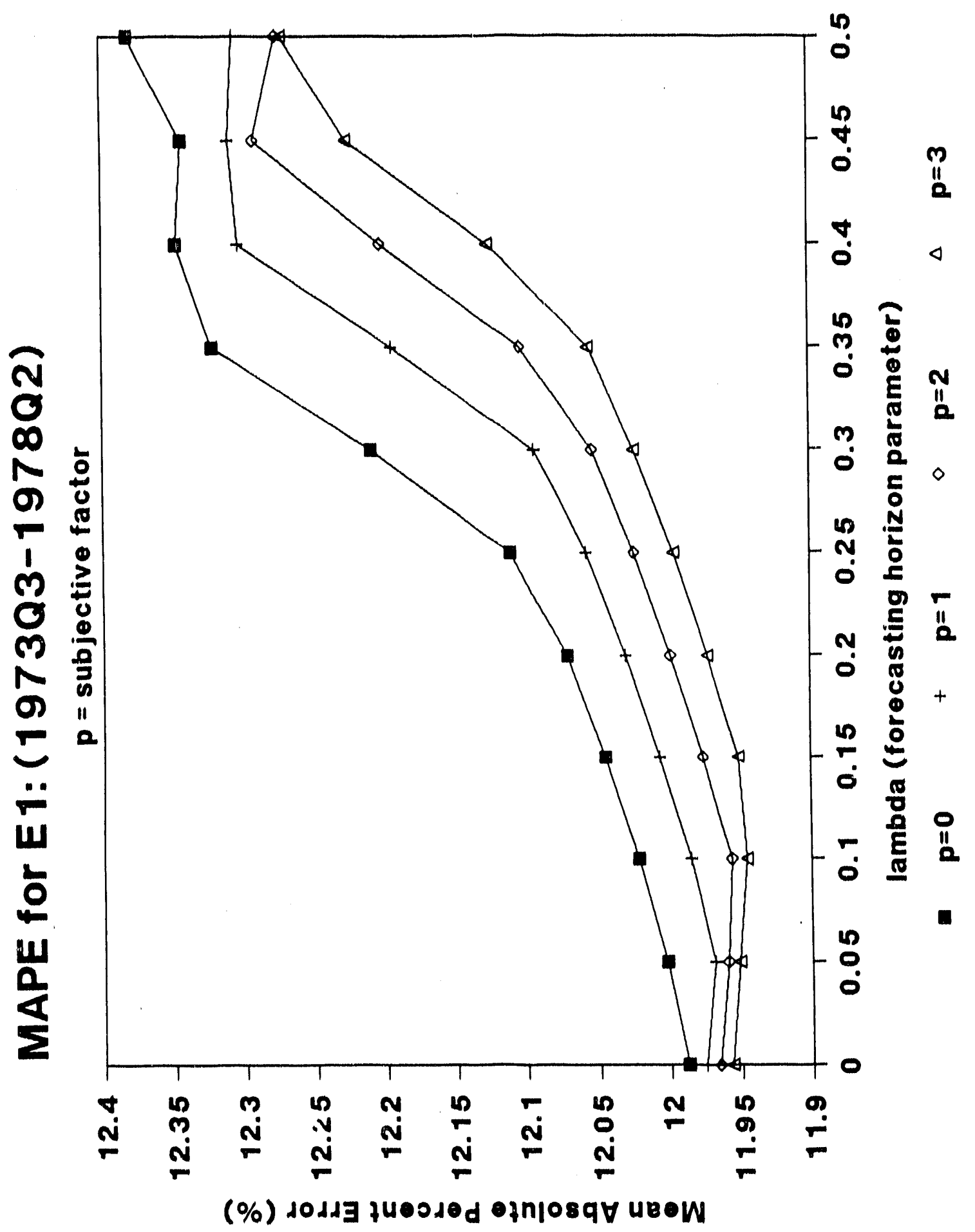


Figure B2

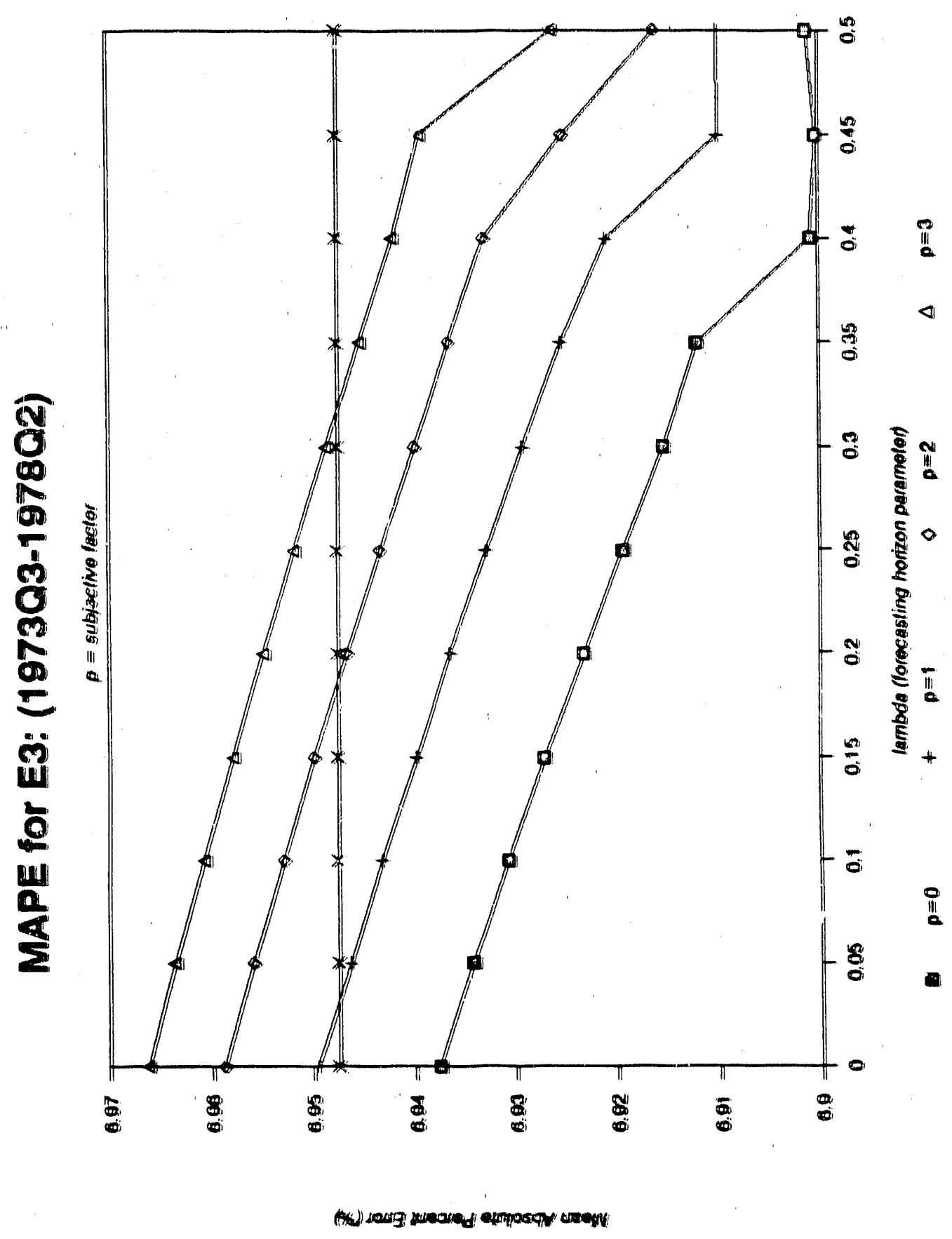


Figure B.3

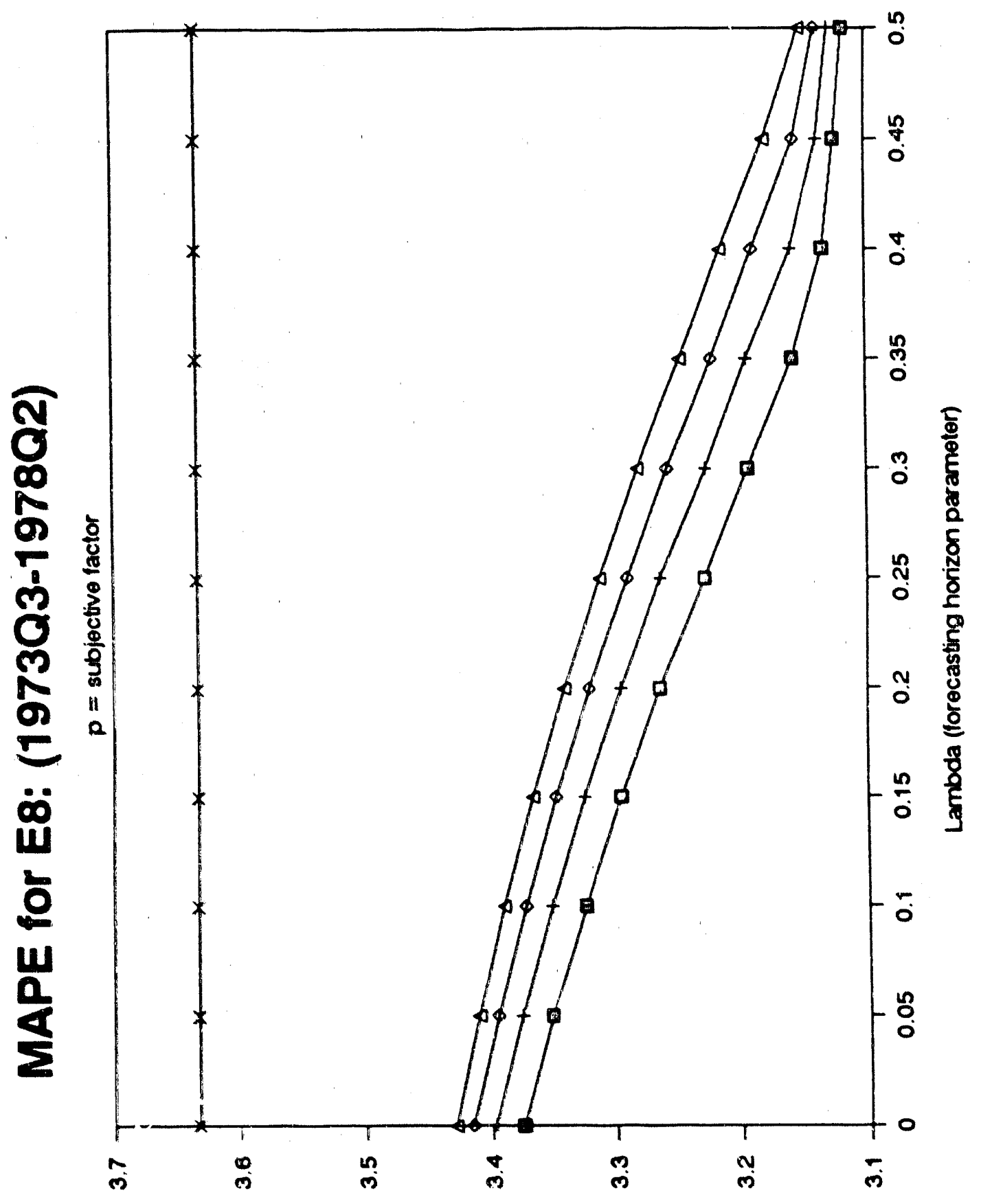

(\%) LoLg Heosed eyposan ueow 
Figure B.4

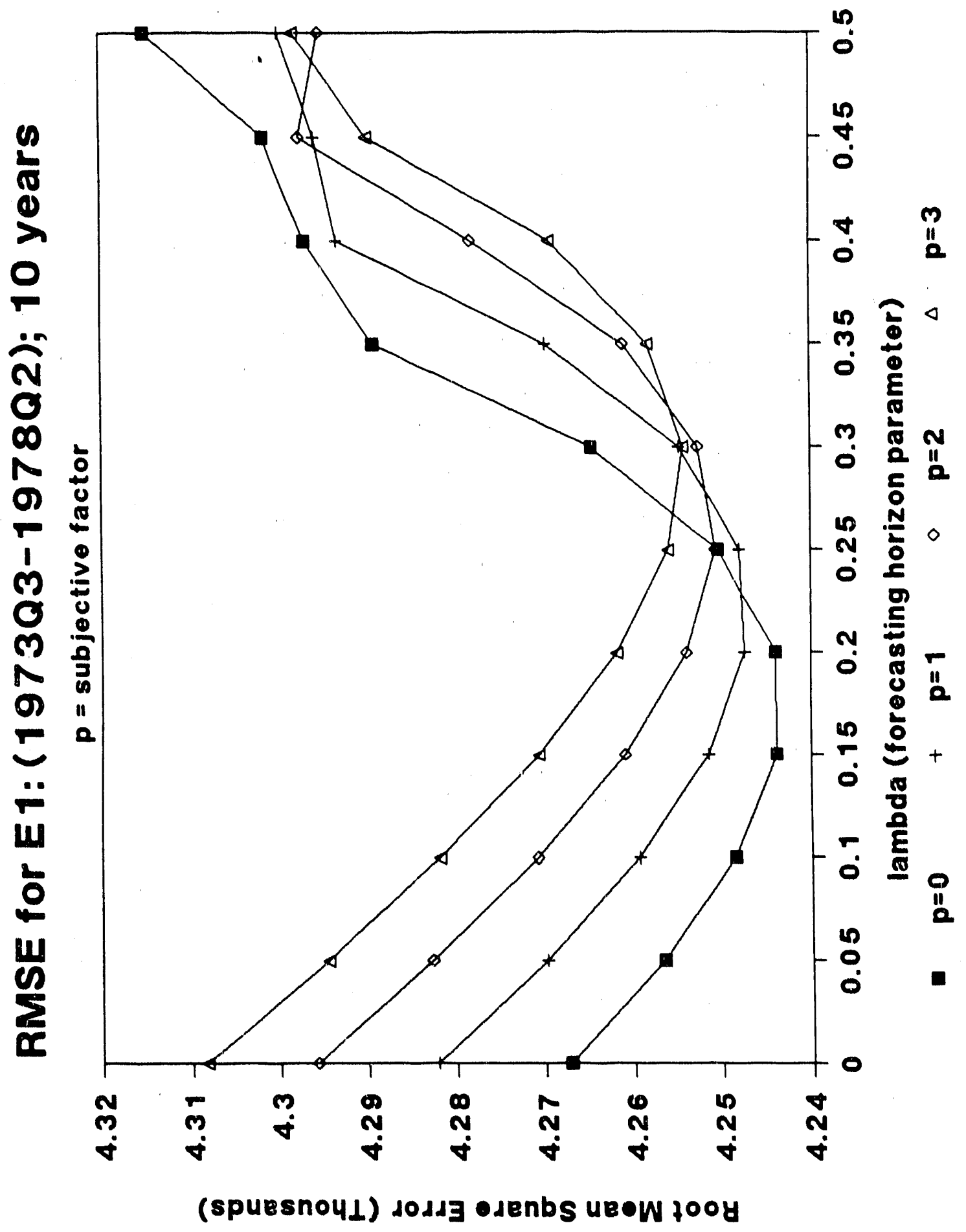

B-7 
Figure B.5

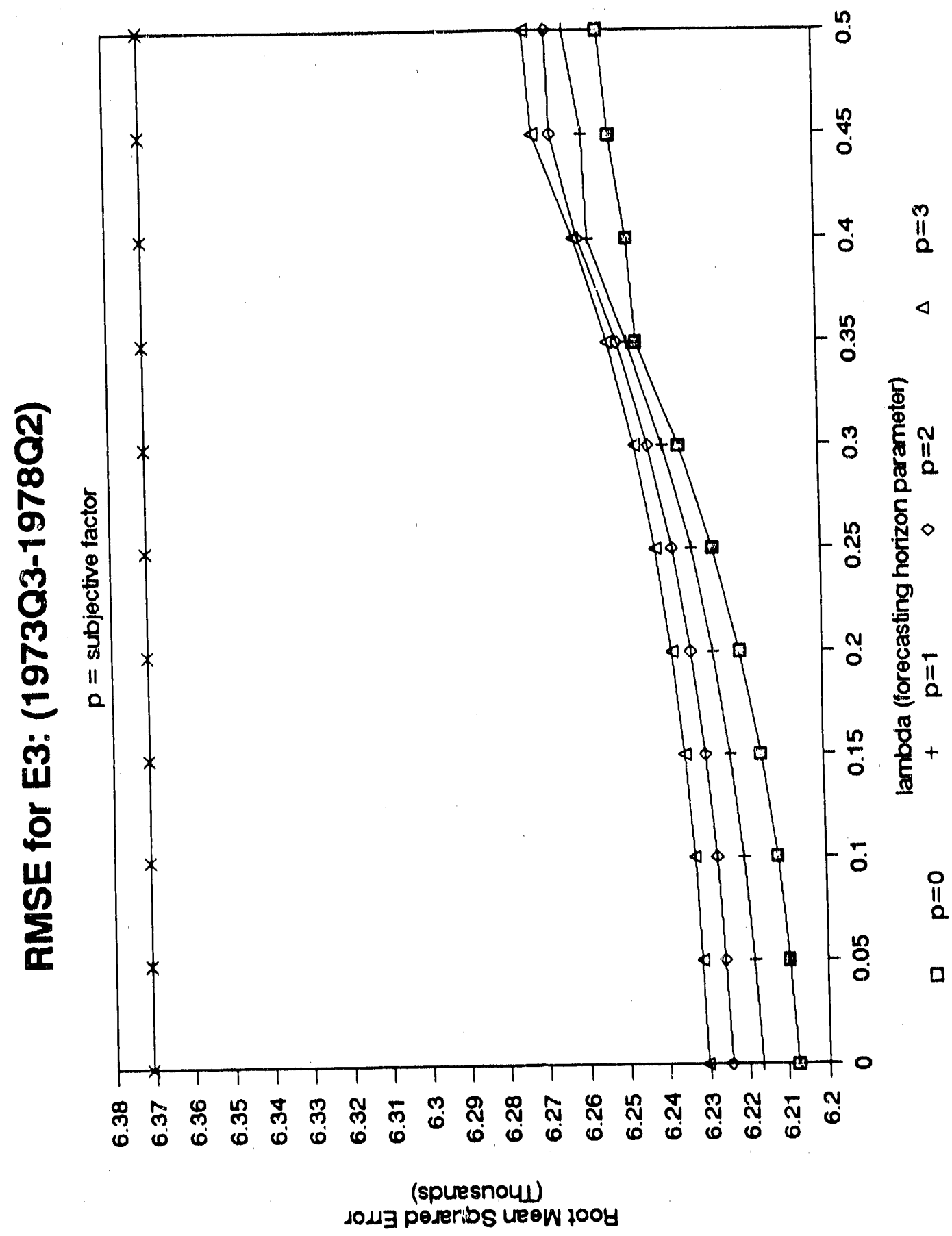


Figure B.6

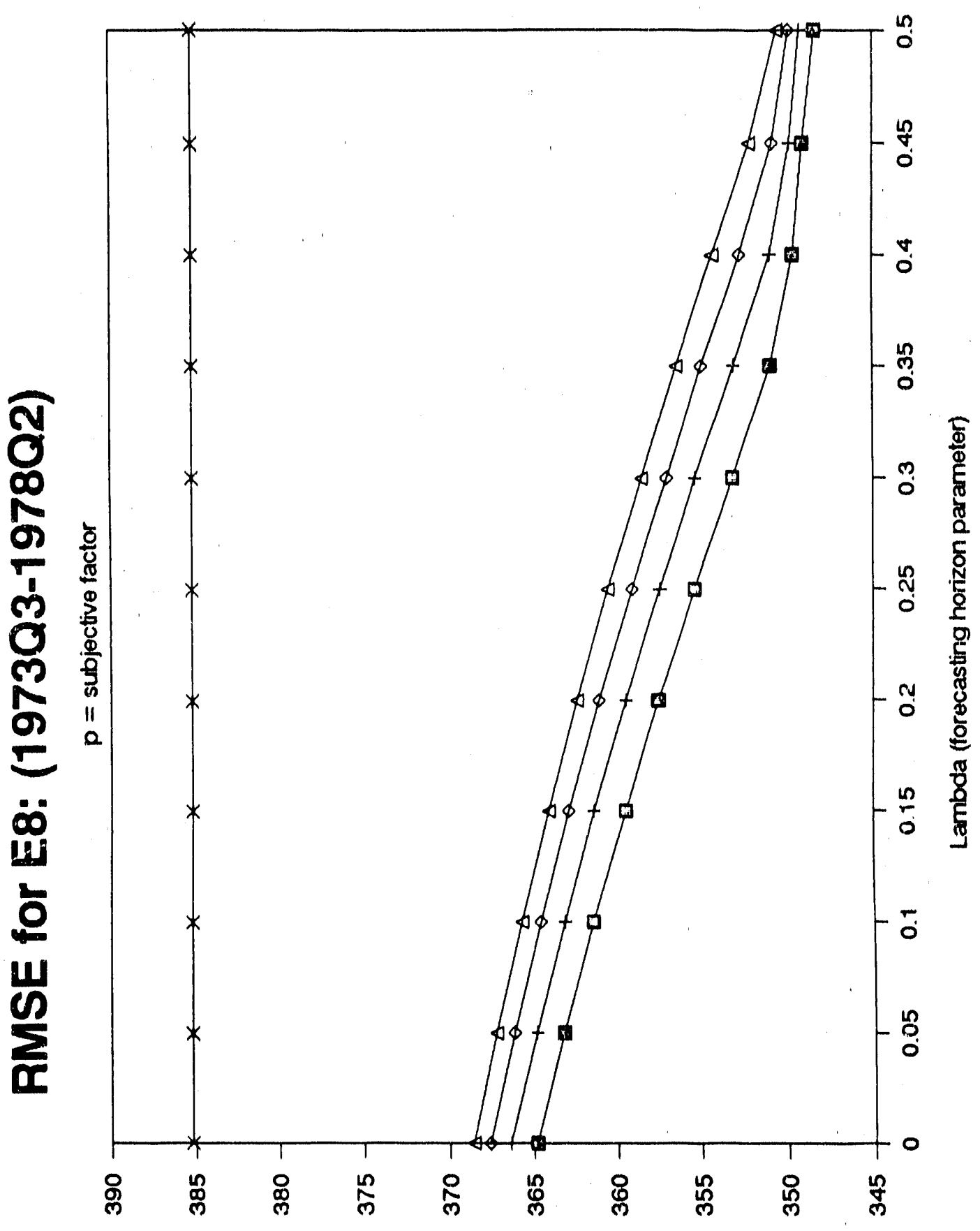

LOLI Posenbs LreeW 1004 

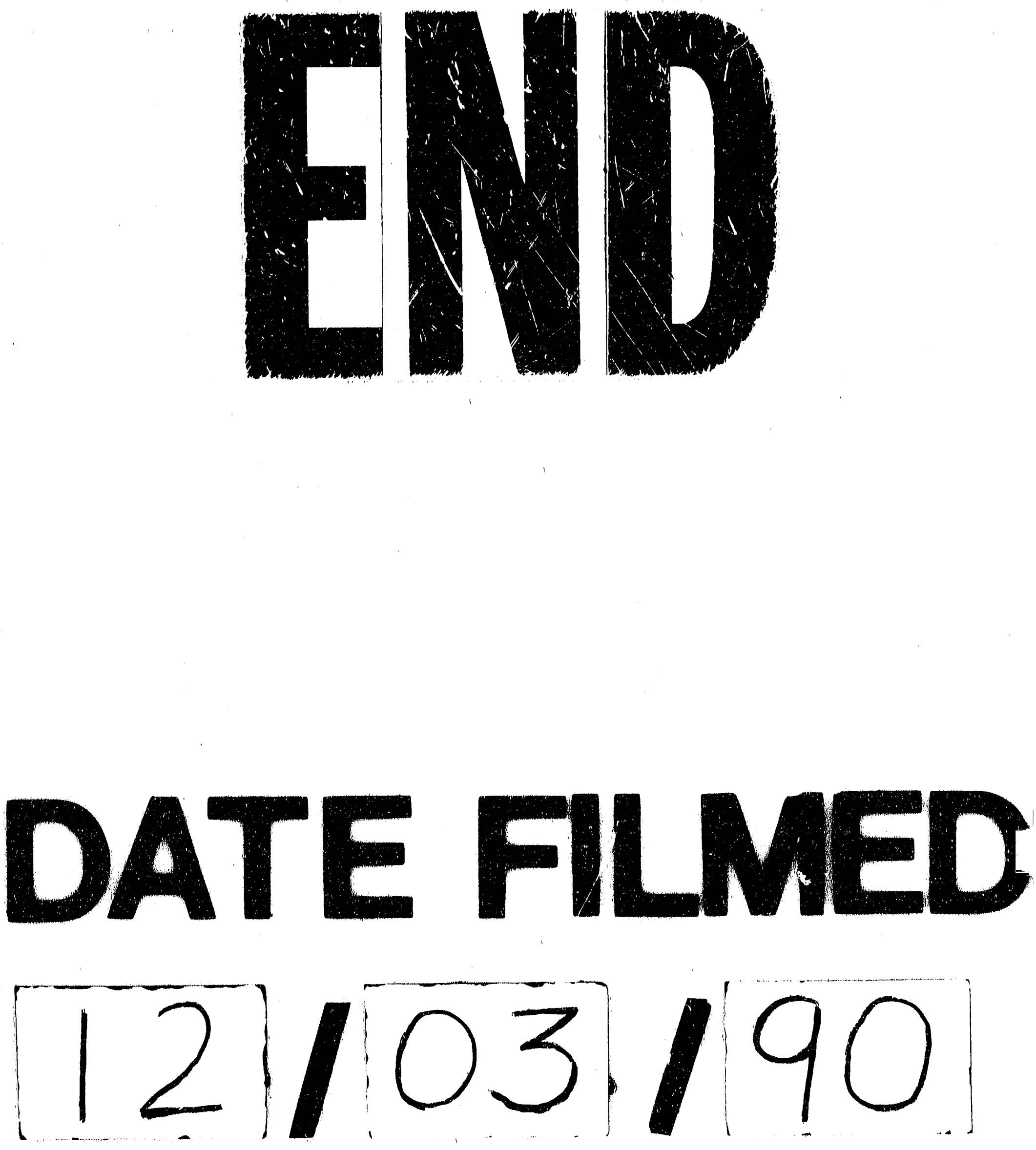
